OPEN ACCESS

Edited by:

Ewelina Szczepanek-Parulska,

Poznan University of Medical

Sciences, Poland

Reviewed by:

Rocco Bruno,

Independent Researcher, Matera, Italy

Trevor Edmund Angell,

University of Southern California,

United States

*Correspondence:

Guang Chen

jidayiyuanjzx@sina.com

Specialty section:

This article was submitted to

Thyroid Endocrinology,

a section of the journal

Frontiers in Endocrinology

Received: 16 August 2018 Accepted: 20 November 2018 Published: 14 December 2018

Citation:

Xue S, Wang P, Hurst ZA, Chang YS and Chen G (2018) Active Surveillance for Papillary Thyroid Microcarcinoma: Challenges and Prospects.

Front. Endocrinol. 9:736.

doi: 10.3389/fendo.2018.00736

\section{Active Surveillance for Papillary Thyroid Microcarcinoma: Challenges and Prospects}

\author{
Shuai Xue ${ }^{1}$, Peisong Wang ${ }^{1}$, Zachary A. Hurst ${ }^{2}$, Yi Seok Chang ${ }^{2}$ and Guang Chen ${ }^{1 *}$ \\ ${ }^{1}$ Thyroid Surgery Department, The First Hospital of Jilin University, Changchun, China, ${ }^{2}$ Department of Physiology and Cell \\ Biology, The Ohio State University, Columbus, $\mathrm{OH}$, United States
}

Active surveillance (AS) can be considered as an alternative to immediate surgery in low-risk papillary thyroid microcarcinoma (PTMC) without clinically apparent lymph nodes, gross extrathyroidal extension (ETE), and/or distant metastasis according to American Thyroid Association. However, in the past AS has been controversial, as evidence supporting AS in the management of PTMC was scarce. The most prominent of these controversies included, the limited accuracy and utility of ultrasound (US) in the detection of ETE, malignant lymph node involvement or the advent of novel lymph node malignancy during AS, and disease progression. We summarized publications and indicated: (1) US, performer-dependent, could not accurately diagnose gross ETE or malignant lymph node involvement in PTMC. However, the combination of computed tomography and US provided more accurate diagnostic performance, especially in terms of selection sensitivity. (2) Compared to immediate surgery patients, low-risk PTMC patients had a slightly higher rate of lymph node metastases (LNM), although the overall rate for both groups remained low. (3) Recent advances in the sensitivity and specificity of imaging and incorporation of diagnostic biomarkers have significantly improved confidence in the ability to differentiate indolent vs. aggressive PTMCs. Our paper reviewed current imagings and biomarkers with initial promise to help select AS candidates more safely and effectively. These challenges and prospects are important areas for future research to promote AS in PTMC.

Keywords: active surveillance, papillary thyroid microcarcinoma, imaging, biomarker, recurrence

\section{INTRODUCTION}

In an early era of medicine, cancer was diagnosed at advanced and incurable stages due to poor diagnostic technologies and limited therapeutic options. High mortality from cancer evoked fear and promoted "early detection and curative treatment" as the holy grail for oncologists (1). Improved technology shifted cancer diagnosis to earlier time-points at less advanced stages, the so called "stage migration." Consequently, detection of sub-clinical small cancers became feasible $(1,2)$. Attributable to improvements in early detection and subsequent increased the number of novel diagnoses, the incidence of localized, in situ, cancers (particularly thyroid, melanoma, and kidney) doubled or tripled between 1975 and 2005 according to SEER database (https://seer.cancer. gov/). Despite the increased incidence, thyroid cancer mortality remains stable (3). Moreover, owing to indolent behavior and favorable prognosis of these cancers, high frequency of occult 
microcarcinoma in autopsy studies has been also reported (49). These evidences indicated that doctors were diagnosing and treating many inert cancers, which would never cause any harm or threaten patient's lives even if left untreated.

Concerns about overdiagnosis and overtreatment lead to the introduction of active surveillance (AS) for indolent cancers, such as low-risk prostate cancer and papillary thyroid cancer, whose 5-year survival rates approached 100\%(10). AS has become a routine treatment strategy for localized prostate cancer (11-13). A randomized controlled trial (ProtecT Trial) with median 10-year follow up reported prostate-cancerspecific-mortality was low among different treatment groups (AS, Surgery and Radiotherapy) and no significant difference existed in overall survival among the three treatment strategies. "Low risk" prostate cancer was defined as clinical stage T1T2a (physical examination and imaging), Gleason Score $\leq$ 6 (biopsy), and prostate specific antigen $<10 \mathrm{ng} / \mathrm{mL}$ (blood test) (14). To date, the most comprehensive study of AS in papillary thyroid microcarcinoma (PTMC) was conducted by the Kuma hospital in Japan. In their prospective trial, $8 \%$ of 1,235 PTMC patients demonstrated tumor enlargement $\geq 3 \mathrm{~mm}$ and $3.8 \%$ demonstrated novel lymph node metastases (LNM) at 10-year follow-up (15). While prognosis for both the immediate surgery and AS cohorts remained excellent, there were significantly less unfavorable events (mainly surgery complications) and medical cost in AS group patients (15). Thus, an increasing number of low-risk PTMC patients in Kuma hospital chose AS as their initial management strategy (16). Per the Kuma hospital criteria, "low risk" PTMC was defined as: no $\mathrm{N} 1$ and $\mathrm{M} 1$; no sign or symptom of invasion to the recurrent laryngeal nerve (RLN) or trachea; no highgrade malignancy in cytology. In contrast to prostate cancer, this criteria for determining AS candidacy in PTMC was heavily dependent on accuracy of imaging, especially ultrasound. Whether imaging examination could rule out small group of aggressive PTMC from AS candidates reliably remains unknown.

On the basis of these limited data, Leboulleux et al. recommended AS with curative intent should be considered in properly selected PTMC patients (17). However, this suggestion was contested by doctors from United Kingdom, United States, China, and Italy, which meant AS was not equally accepted by all physicians around the world. Clinicians showed little acceptance of AS because they believed evidence to support AS in PTMC was insufficient (18). In contrast to prostate cancer, thyroid cancer patients have better prognoses and lower mortality. However, the utility of AS in thyroid cancer remains controversial. Patients and clinicians alike worry delaying immediate treatment, as would be indicated by AS, may result in more extensive surgical intervention should substantial disease progression occur from the time of initial diagnosis. To address these concerns, it is essential to critically evaluate the ability of diagnostic imaging and biomarkers to accurately stratify risk in PTMC patients.

\section{DIAGNOSTIC ACCURACY OF PREOPERATIVE US}

\section{Extrathyroidal Extension (ETE)}

ETE, defined as tumor spread outside of the thyroid gland and into the surrounding tissues, occurs in up to $30 \%$ of differentiated thyroid cancer cases (19-23). Minimal ETE, detectable only on histological examination, was not a risk factor for disease specific survival and disease related mortality. Gross ETE, or macroscopic ETE, predicted increased recurrence and mortality (24). Thus, the general consensus is to consider gross ETE as an absolute indication for total thyroidectomy and administration of postoperative radioactive iodine (25). Differentiating minimal from gross ETE is essential in the selection of candidates for AS, however, to date, there is no reliable data to evaluate the diagnostic accuracy of ultrasound (US) alone for gross ETE in PTMC. As shown in Table 1, several studies assessed diagnostic ability of US for ETE (minimal and gross) in PTC or PTMC (26-33). The sensitivity and specificity of US ranged from 25 to $100 \%$ and from 13 to $93 \%$, respectively. The huge variation in accuracy of US among different studies may result from (1): different percentage of minimal and gross ETE; (2): different diagnostic criteria of US; and (3): different levels of experience of the US technicians. Furthermore, we extracted 9 cases of T4 PTC patients from 5 articles and found that only 1 patient was diagnosed correctly by US, as shown in Table 2 (30, 34-37). That indicates US alone, which is dependent on the experience of the technician and interpreting physician, can't be used to reliably diagnose gross ETE in PTMC.

Tracheal and RLN invasiveness are the most commonly observed gross ETE. Consequently, the Kuma hospital elected to implement "no signs or symptoms of invasion to RLN or trachea" as their selection criteria for AS in PTMC (15). In 2005, a study from Kuma hospital demonstrated US could diagnose tracheal invasion of PTC with extremely favorable sensitivity, specificity, and accuracy of 91, 93, and 93\%, respectively (27). Moreover, Ito from Kuma hospital diagnosed tracheal invasion from low-risk PTMC based on the angles between tumor and tracheal wall with $100 \%$ sensitivity and $94.5 \%$ specificity, while diagnosis of RLN invasion was based on whether the normal rim of the thyroid was clearly present in the direction of RNL with $100 \%$ sensitivity and $90.3 \%$ specificity. However, 841 (74\%) lowrisk PTMC patients in this study were diagnosed with help of plain neck computed tomography (CT) because of uncertainty in US imaging. A study enrolled 377 PTC patients demonstrated the combination of US and CT scan decreased the false negative and false positive rates, improving ETE prediction accuracy. In a subgroup of PTMC, the combination of US and CT features also increased positive predictive value (PPV) remarkably (31). Choi et al. demonstrated that contrast-enhanced CT imaging correctly diagnosed a PTC patient as T4, while US alone would have categorized the patient as T3. However, they indicated the combined use of contrast-enhanced CT imaging and US did not improve accuracy for the diagnosis of minimal ETE in PTMC patients (35). 
TABLE 1 | Diagnostic accuracy of preoperative ultrasound for extrathyroidal extension in thyroid cancer.

\begin{tabular}{|c|c|c|c|c|c|c|c|c|c|}
\hline References & Country & Study & Patients & Criteria & SE (\%) & SP (\%) & PPV (\%) & NPV (\%) & $\mathrm{AC}(\%)$ \\
\hline Shimamoto et al. (26) & Japan & SR & 35 of 77 with ETE (minimal and gross) & A & 80 & 73.8 & 71.8 & 81.6 & 76.6 \\
\hline Tomoda et al. (27) & Japan & SR & 13 of 509 with $\mathrm{TI}$ & C & 91 & 93 & 25 & 99 & 93 \\
\hline Kwak et al. (28) & South Korea & $\mathrm{SR}$ & 89 of 221 with ETE (N/A) & A & 65.2 & 81.8 & 70.7 & 77.7 & $\mathrm{~N} / \mathrm{A}$ \\
\hline Kim et al. (29) & South Korea & SR & 67 of 75 with ETE (minimal and gross) & $A, C, D$ & 78.5 & 79.5 & 46.8 & 94.1 & 79.3 \\
\hline Lee et al. (30) & South Korea & SR & 174 of 377 with ETE (N/A) & A & 66.1 & 65.1 & 72.2 & 58.3 & $\mathrm{~N} / \mathrm{A}$ \\
\hline Lee et al. (31) & South Korea & SR & 275 of 568 with ETE (minimal and gross) & A & 83.3 & 68.9 & 71.6 & 81.5 & 75.9 \\
\hline Moon et al. (32) & South Korea & SR & 26 of 105 with EFI & $E$ & 46.2 & 97.5 & 85.7 & 84.6 & 84.8 \\
\hline Kamaya et al. (33) & USA & SR & 16 of 62 with ETE (minimal and gross) & $A, B$ & 25 & 93 & 57 & 78 & $\mathrm{~N} / \mathrm{A}$ \\
\hline
\end{tabular}

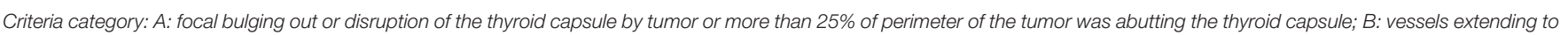

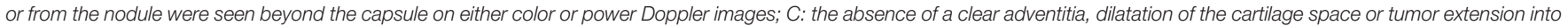

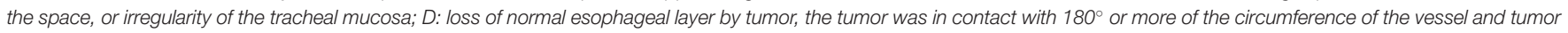

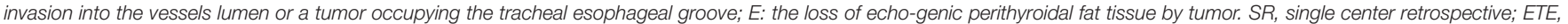

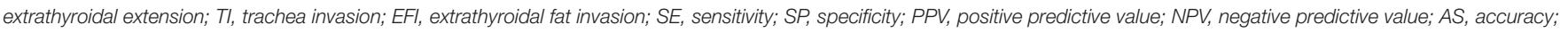
N/A, not available.

TABLE 2 | Diagnostic accuracy of preoperative ultrasound for pathologic T4 papillary thyroid carcinoma.

\begin{tabular}{llcccc}
\hline References & Country & Study & T4 Patients & Criteria & $\begin{array}{c}\text { US } \\
\text { accuracy }\end{array}$ \\
\hline King et al. (34) & Hong Kong & SP & 3/14 of PTC & A & 0/3 \\
Choi et al. (35) & South Korea & SR & $1 / 299$ of PTC & B & 0/1 \\
Park et al. (36) & South Korea & SP & $1 / 94$ of PTC & B,C & 0/1 \\
Choi et al. (37) & South Korea & SR & $1 / 722$ of PTC & B & $1 / 1$ \\
Lee et al. (30) & South Korea & SR & $3 / 568$ of PTC & B & $0 / 3$ \\
\hline
\end{tabular}

Criteria category: A: poorly defined margin with heterogeneous echogenicity in adjacent fat or muscle or tumor invasion into the lumen; $B$ : focal bulging out or disruption of the thyroid capsule by tumor or more than $25 \%$ of perimeter of the tumor was abutting the thyroid capsule; C, tumor diameter. SP, single center prospective; $S R$, single center retrospective; PTC, papillary thyroid carcinoma; US, ultrasound.

Currently, there are very few studies reporting RLN invasion in PTMC, presumably due to the low incidence of RLN invasion in PTMC. Ito et al. found only 9 of 1,143 PTMC patients with RLN invasion, all 9 of whom had a tumor diameter of $7 \mathrm{~mm}$ or larger. Consequently, Ito et al. concluded tumors of $<7 \mathrm{~mm}$ in their largest diameter were unlikely to have RLN invasion. But PTMC was derived from abnormal follicular epithelial cell which meant it could be located anywhere within the thyroid. Small PTMCs $(<5 \mathrm{~mm})$ which invade RLN were more likely located in the dorsal part of thyroid. Inaccurate identification for boundaries of small PTMCs and dorsal membrane of thyroid by US may lead to misdiagnosis of gross ETE. Due to limitations in US at the time of evaluation, ETE in these patients was incorrectly assessed. The evidence reminds us of the limited efficacy for US alone in predicting gross ETE and that not all PTMC patients are low risk.

\section{Lymph Node Metastases}

LNM to the central and lateral compartments are common occurrences in PTC, and increase the rate of loco-regional recurrence and mortality, especially among old patients (38).
Nearly $80 \%$ of PTC patients had micrometastatic lymph nodes on postoperative pathologic examination while $30 \%$ had clinical lymph nodes on initial presentation $(39,40)$. However, as shown in Table 3, the accuracy of preoperative US for diagnosing metastatic lymph nodes is low $(26,35,36,41-52)$. Appropriate selection of candidates for AS requires high sensitivity in order to prevent the enrollment of higher-risk PTMC patients. To predict central lymph node metastases (CLNM), sensitivity of US ranged from 22.6 to $55 \%$, meaning nearly half of CLNM were not correctly diagnosed. This is perhaps due to the difficulty in detecting metastatic lymph nodes in the retropharynx, superior mediastinum, and deep trachea-esophageal groove. In contrast to CLNM, US sensitivity to detect lateral lymph node metastases (LLNM) was much better (62 to 100\%). Of note, micrometastases are less important clinically compared to macrometastases. The benefit of treating incidentally identified micro-metastases are not well-demonstrated. Consequently, the American Thyroid Association (ATA) recommended fine needle aspiration (FNA) only for suspicious cervical lymph nodes larger than 8-10 mm (25). Among the articles we summarized in Tables 3, 5 studies focused on metastatic lymph nodes larger than $8-10 \mathrm{~mm}(26$, $35,47,50,52)$. However, the sensitivity of US for diagnosing CLNM remained low (26-53.2\%). US didn't show any advantages in diagnostic ability for larger metastatic lymph nodes compared with the micrometastases.

Shown in Figure 1 and Table 4, standalone CT imaging, or CT combined with US remarkably increased CLNM and LLNM diagnostic sensitivity and accuracy $(35,42,43,48,50)$. In Choi's study which focused on metastatic lymph nodes larger than $10 \mathrm{~mm}$, combination of US and CT increased sensitivity of CLNM from 53.2 to $73 \%$, and LLNM from 93.9 to $95.9 \%$ (35). A separate prospective study from United States demonstrated that the combination of US and CT increased sensitivity of detecting metastatic central and lateral lymph node significantly to $54,97 \%$, respectively. Accordingly, they suggested combination of US and CT could provide reliable preoperative macroscopic nodal metastasis information to design rational nodal surgery in PTC patients (50). 
TABLE 3 | Diagnostic accuracy of preoperative ultrasound for metastatic lymph nodes in thyroid cancer.

\begin{tabular}{|c|c|c|c|c|c|c|c|c|c|c|}
\hline References & Country & Study & Patients & Criteria & Compartment & SE (\%) & SP (\%) & PPV (\%) & NPV (\%) & $A C(\%)$ \\
\hline Shimamoto et al. (26) & Japan & $\mathrm{SR}$ & 49 N1 of 77 PTC & $A, B$ & CLNM, LLNM & 36.7 & 89.3 & 85.7 & 44.6 & 55.8 \\
\hline Jeong et al. (35) & South Korea & $\mathrm{SP}$ & 46 positive LNs of 312 LNs & $A$ & CLNM, LLNM & 53.6 & 97.9 & 73.7 & 95 & $\mathrm{~N} / \mathrm{A}$ \\
\hline \multirow[t]{2}{*}{ Kim et al. (41) } & South Korea & SR & 53 N1 of 165 PTC & A & CLNM & 38 & 93 & 77 & 70 & 71 \\
\hline & & & & & LLNM & 64 & 92 & 83 & 82 & 82 \\
\hline \multirow[t]{2}{*}{ Sugitani et al. (42) } & Japan & $\mathrm{SP}$ & 263 N1 of 361 PTC & $A$ & CLNM & 29 & 91 & 82 & 47.3 & 48.3 \\
\hline & & & & & LLNM & 100 & 0 & 98 & 0 & 98 \\
\hline \multirow[t]{2}{*}{ Ahn et al. (36) } & South Korea & SR & $\begin{array}{l}117 \text { positive levels of } 183 \\
\text { cervical level }\end{array}$ & A & CLNM & 55 & 69 & 77 & 44 & 60 \\
\hline & & & & & LLNM & 62 & 79 & 84 & 55 & 68 \\
\hline \multirow[t]{2}{*}{ Choi et al. (43) } & South Korea & SR & 119 N1 of 299 PTC & $A, B$ & CLNM & 53.2 & 79.8 & 60.8 & 74.3 & 69.9 \\
\hline & & & & & LLNM & 93.9 & 25 & 93.9 & 25 & 88.7 \\
\hline \multirow[t]{2}{*}{ Park et al. (44) } & South Korea & SR & 34 N1 of 94 PTC & A & CLNM & 22.6 & 98.6 & 87.5 & 74.5 & 70.1 \\
\hline & & & & & LLNM & 76.2 & 75 & 72.7 & 78.3 & 75.6 \\
\hline \multirow[t]{2}{*}{ Choi et al. (45) } & South Korea & SR & 238 N1 of 589 PTC & $A$ & CLNM & 47.2 & 94.8 & 90.4 & 63.5 & 70.6 \\
\hline & & & & & LLNM & 69.1 & 94.8 & 57.6 & 96.8 & 92.4 \\
\hline Lee et al. (46) & Japan & SR & 254 positive LNs of 331 LNs & A & CLNM, LLNM & 78 & 99 & 99.5 & 58 & 83 \\
\hline \multirow[t]{2}{*}{ Hwang et al. (47) } & USA & SR & 30 N1 of 68 PTC & $A, B$ & CLNM & 30 & 86.8 & 64.3 & 61.1 & $\mathrm{~N} / \mathrm{A}$ \\
\hline & & & & & LLNM & 93.8 & 80 & 76.5 & 94.1 & $\mathrm{~N} / \mathrm{A}$ \\
\hline \multirow[t]{2}{*}{ Lee et al. (48) } & South Korea & SR & $121 \mathrm{~N} 1$ of 252 PTC & A & CLNM & 23 & 97 & 81 & 72 & 73 \\
\hline & & & & & LLNM & 70 & 84 & 81 & 74 & 77 \\
\hline Yoo et al. (49) & South Korea & SR & 51 positive LNs of 124 LNs & A & CLNM & 76.4 & 69.9 & 63.9 & 81 & 72.6 \\
\hline \multirow[t]{2}{*}{ Lesnik et al. (50) } & USA & $\mathrm{SP}$ & 162 PTC & $A, B$ & CLNM & 26 & 95 & 78 & 66 & $\mathrm{~N} / \mathrm{A}$ \\
\hline & & & & & LLNM & 79 & 87 & 80 & 86 & N/A \\
\hline \multirow[t]{2}{*}{ Lee et al. (51) } & South Korea & SR & 136 N1 of 368 PTC & A & LLNM & 39 & 88.4 & 66.3 & 71.2 & 70.1 \\
\hline & & & 44 N1 of 48 PTC & & LLNM & 95.5 & 25 & 93.3 & 33.3 & 89.6 \\
\hline Khokhar et al. (52) & USA & $\mathrm{SR}$ & 104 N1 of 227 PTC & $A, B$ & CLNM & 37.5 & 90.2 & 76.5 & 63.1 & 66.1 \\
\hline
\end{tabular}

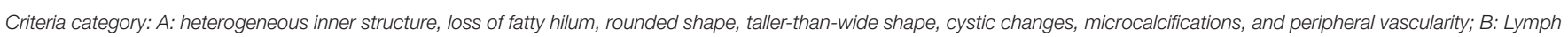

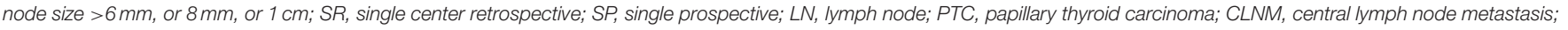
LLNM, lateral lymph node metastasis; SE, sensitivity; SP, specificity; PPV, positive predictive value; NPV, negative predictive value; AS: accuracy; N/A, not available.

The limitations of US to detect thyroid nodule and cervical lymph nodes were operator-dependent, presumably due to difficultly in evaluating deep anatomic structures such as mediastinum, parapharyngeal, retropharyngeal and infraclavicular regions, acoustically shadowed by bone, calcification or air (66). As a result, the 2015 ATA guideline recommended preoperative $\mathrm{CT}$ as an adjunct to US for patients with large or invasive primary tumor or US suspected advanced disease (25). Nevertheless, is it possible to diagnose gross ETE with virtually $100 \%$ sensitivity, as reported by the Kuma hospital? Could we diagnose cervical macroscopic LNM with decent sensitivity only by US? As summarized above, it may be possible to approach this high sensitivity through the combination of diagnostic CT and US imaging, which demonstrated significant improvements in diagnostic performance compared to US alone.

\section{Radiologist vs. Surgeon Performed US}

Multiple studies demonstrated that radiologist-performed USs were less accurate and provided inadequate preoperative staging when compared to surgeon-performed USs (67-70). Nearly half of patients received incorrect initial surgery with high local recurrence when an operation decision was made only based on radiologist-performed USs. Denise Carneiro-Pla reported surgeon-performed US changed the therapeutic strategy of $45 \%$ thyroid cancer patients through the accurate identification of CLNM/LLNM and thyroid intrathoracic extension (69). Rosebel Monteiro demonstrated that metastatic lymph nodes were diagnosed more frequently by CT imaging than US (70.8 vs. $54 \%)$. Moreover, surgeon-performed US was only able to detect $45 \%$ of metastatic lymph nodes in a cohort comprised of patients with LLNM (67). In the Kuma hospital, US was performed by specially trained sonographers and retrospectively reviewed by surgeons (15). Thus, it is extremely important to note that the appropriate selection of low-risk PTMC patients for AS is limited by the experience, or inexperience, of diagnosing physicians. Addressing this issue means improvements in both imaging technologies and in the education of physicians play important roles in AS candidate selection.

\section{NOVEL LNM DURING AS}

Sixteen percent of AS patients will require surgical intervention due to disease progression $(71,72)$. However, despite disease progression, prognosis in these patients remains remarkably 

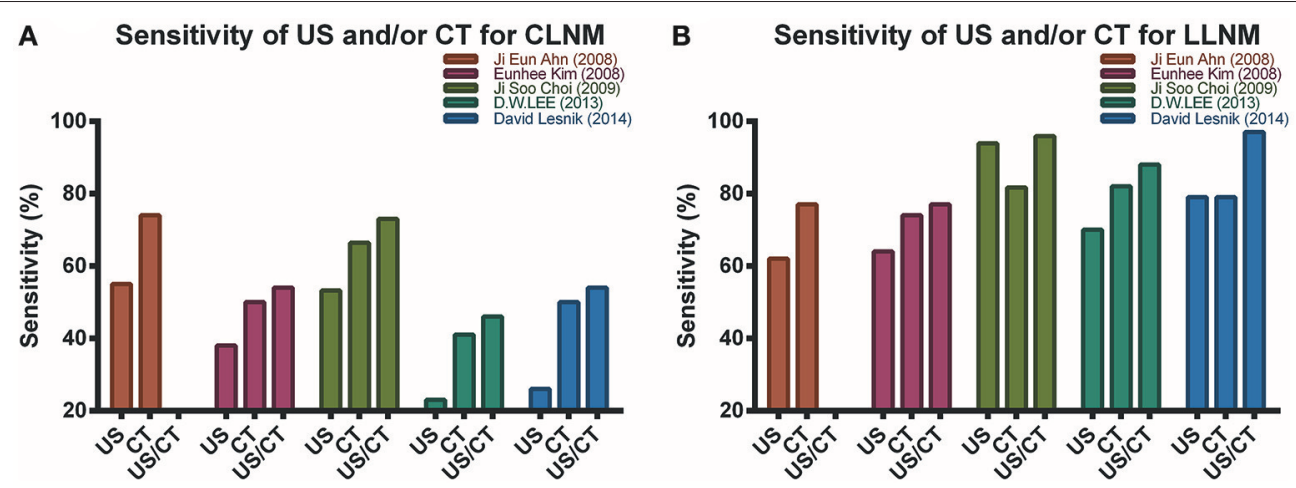

FIGURE 1 | Diagnostic sensitivity was improved by CT alone or combination of US and CT for CLNM (A) and LLNM (B). Overall sensitivity of US and/or CT for LLNM was higher than for CLNM. Among Choi (43) and Lesnik (50) studies which only evaluated cervical lymph nodes larger than $10 \mathrm{~mm}$, the combination of US and CT also provided highest sensitivity. The sensitivity for diagnosis of CLNM and LLNM by combination of US and CT was not evaluated in Ahn study (35).

TABLE 4 | Diagnostic accuracy of preoperative ultrasound and computed tomography for metastatic lymph nodes in thyroid cancer.

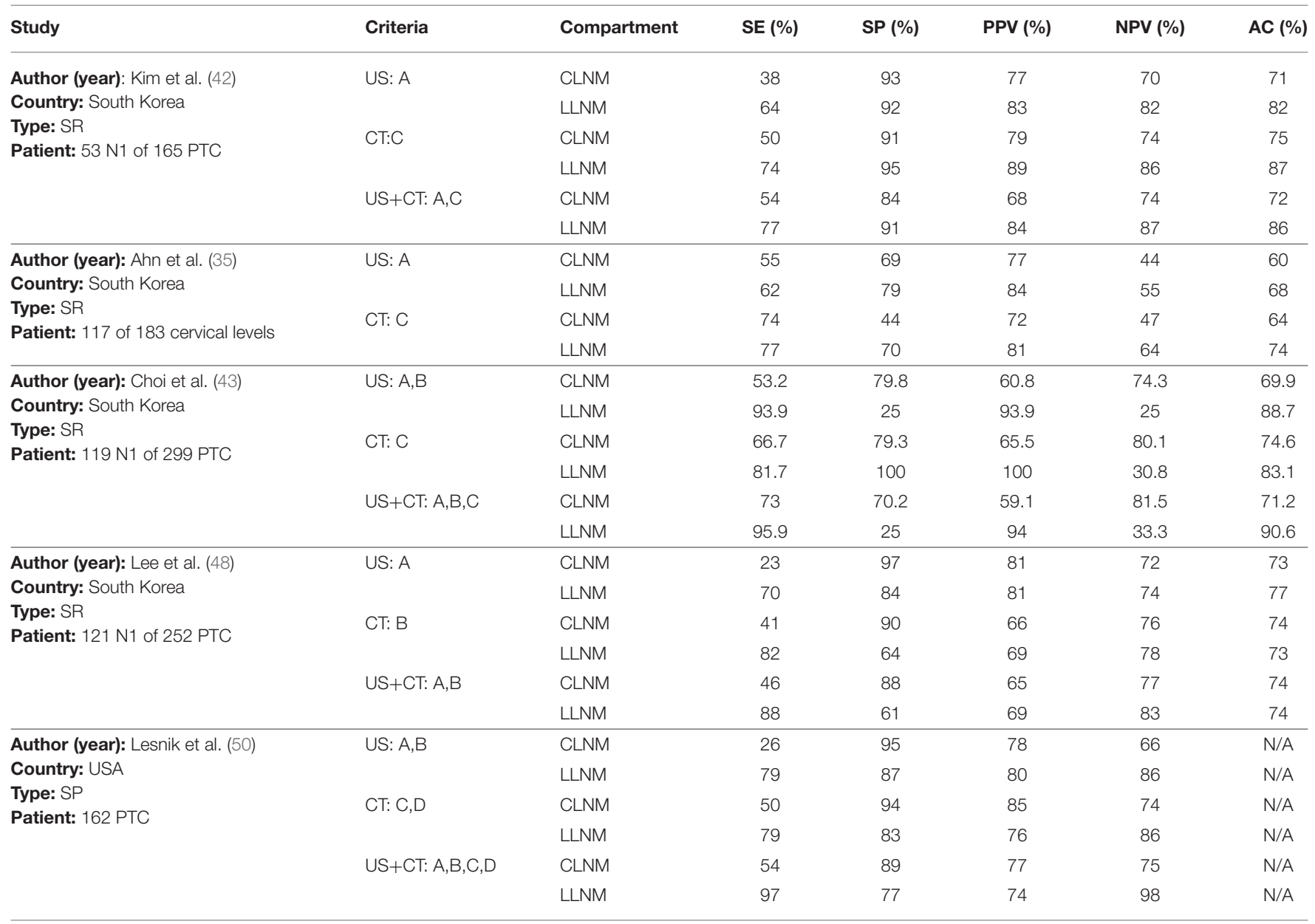

US criteria category: A: heterogeneous inner structure, loss of fatty hilum, rounded shape, taller-than-wide shape, cystic changes, microcalcifications, and peripheral vascularity; B:

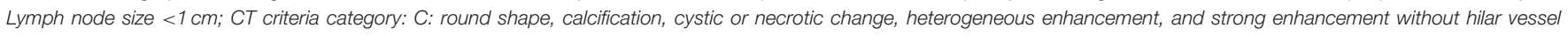

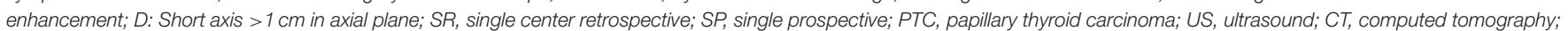

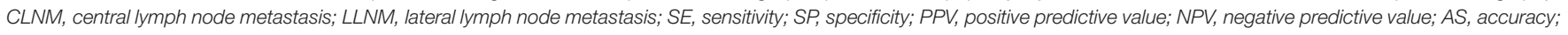
N/A, not available. 
excellent due to the success of salvage surgery (15). In certain circumstances, most commonly the appearance of a novel LNM in the lateral/central compartment, delayed surgical intervention may increase the risk of subjecting a patient to more invasive surgical procedures, an increased risk of recurrence, and more extensive follow-up. A retrospective study which enrolled 8,808 PTMC in Korea demonstrated 12 PTMC with distant metastases had cervical lymph node involvement. Among them, 10 patients had clinically apparent lateral lymph nodes, while 2 had microscopic CLNM (73). Xu et al. investigated 3,750 non-anaplastic follicular cell-derived thyroid carcinomas and found that, of the 3 PTMC-related deaths, all 3 patients had clinically apparent cervical lymph nodes (74). Clinically apparent cervical lymph nodes were positively related with recurrence, distant metastases, and disease-specific mortality. Consequently, patients in which cervical lymph node involvement is detected during follow-up, no longer benefit from AS, and additional therapeutic intervention should be explored. According to a series of studies from Kuma hospital, the rates of novel lymph node appearance among patients undergoing AS were 1.2, 1.5, and $2.1 \%$ with an average of $3.9,5$, and 6.2 years of observation, respectively $(72,75,76)$. Ito et al. explained that LNM may occur prior to, or at a very early stage of, PTMC diagnosis. Consequently, immediate surgery will not prevent metastases to the neck lymph node(s) and these patients will have recurrence and require a salvage operation in the future regardless of the initial management strategy (15). However, it is debated as to whether novel LNM during AS are completely comparable to recurrent lymph node involvement in an immediate surgery cohort, as it is difficult to demonstrate whether the tumor cells disseminate into lymph node during AS or before diagnosis.

If early dissemination of tumor cells to a regional or distant lymph node has occurred prior to diagnosis and/or initial thyroidectomy, excision of the primary thyroid cancer is unlikely to prevent recurrent disease localized to the lymph nodes. The parallel progression hypothesis, defined as the capacity of tumor cells to spread to the lymph nodes or more distant sites from the primary tumor site at a very early stage of tumorigenesis leading to the independent progression/evolution of a metastatic site, may explain early dissemination and frequent lymph node recurrence after surgery (77). PTC recurs much more frequently at central or lateral lymph node than thyroid bed after surgery $(55,78,79)$, suggesting that recurrent lymph nodes of the neck had an early dissemination event prior to excision of the primary PTC.

Microscopic metastasis in regional lymph nodes was present in up to $63.83 \%$ of PTMC patients, although the recurrence rate was much lower to $1-5 \%(17,80)$. The mechanism of lymph node recurrence after initial surgery without prophylactic lymph node dissection was possibly the outgrowth of micro-metastatic deposits into overt tumors. Whether or not a population of microscopic tumor cells can transform into clinically apparent lymph nodes may depend on not only the intrinsic genetic alterations of the cancer cells themselves but also the state of the host environment (81). It is well-known that both the local tissue microenvironment and the systemic physiological environment play significant roles in regulating dormant disseminated tumor cells into gross metastasis. Additionally, the tumor microenvironment can change during multiple steps of tumor progression and metastases, which could either inhibit or facilitate the progression of microscopic lymph nodes to clinically apparent lymph nodes (82-84). Perhaps, however, there exists a connection between persistent tumor foci in the thyroid and the progression of LNM from microscopic to clinically apparent.

We summarized 13 PTMC cohorts, each containing more than 200 patients, who received immediate surgery, shown in Table 5 (53-65). We hypothesize, that AS patients should have a lower rate of novel clinically apparent metastatic lymph nodes than the rate of recurrent lymph nodes in PTMC cohort with gross ETE and/or palpable lymph nodes. However, as shown in Figure 2, we found novel LNM during AS was not less than lymph node recurrence rate among 6 of 11 PTMC cohorts with median follow-up time $<10$ years. Meanwhile, 5 of these 11 cohorts had relatively higher lymph node recurrence rates than AS group because all of these cohorts had patients with gross ETE and clinical involved lymph nodes. Among these 13 PTMC cohorts, there were two studies which enrolled low-risk PTMC patients without gross ETE or clinically apparent lymph nodes. Their lymph node recurrence rates were 1.2 and $0.7 \%$ with 5.4 and 5.8-year follow up, which were less than 1.5 and $2.1 \%$ of novel lymph node appearance rate with 5- and 6.2-year observation time in AS cohort from Kuma hospital $(64,65,72,76)$. With limited data, the rate of clinical apparent LNM in low-risk PTMC patients under AS seems to be a little higher than patients with immediate surgery. Considering cofounders between different patient's cohorts, this preliminary result needs to be supported and proved by more evidence in the future. Oda et al. compared clinicopathological and prognostic features of low-risk PTMC between AS and immediate surgery groups with a comparable experimental timeline. They found novel LNM appeared in 6 of 1179 AS patients (0.5\%), whereas only 2 of $974(0.2 \%)$ patients choosing immediate surgery experienced recurrence in cervical lymph nodes although this difference was not statistically significant (85). A study from Italy which enrolled 312 very lowrisk PTMC (No family history of thyroid cancer; No history of head and neck irradiation; Tumor staging: T1 $1 \mathrm{~cm}$ or less, N0, M0; No extension beyond thyroid capsule; Unifocal; Not aggressive histologic subtype; Not locally invasive) with 6.7-year follow up demonstrated none of the patients had lymph node recurrence (86). In addition, another study from Kuma hospital found up to $11 \%$ of PTMC in cohort of young patients aged 20 to 29 had novel LNM with median 5.5-year follow up (87). If novel LNM in AS group was completely comparable with lymph node recurrence in an immediate surgery cohort, should $11 \%$ of lowrisk PTMC in $20 \mathrm{~s}$ group who underwent immediate surgery have lymph node recurrence after 5.5-year follow up? Patient age was believed to be predictor for novel lymph node appearance during AS $(72,87)$. However, age was not a risk factor for cervical lymph node recurrence in PTMC patients $(79,88)$.

In contrast to AS, the benefits of immediate surgery may include: (1) A more accurate risk stratification can be made using information gathered from histological or genetic evaluation of a biopsy obtained from surgery, than can be obtained from imaging data alone. (2) TSH suppression after surgery would 
TABLE 5 | Cervical lymph node recurrence rate in different papillary thyroid microcarcinoma cohorts with immediate surgery.

\begin{tabular}{|c|c|c|c|c|c|c|c|c|}
\hline References & Country & No. of patients & Gross ETE (n, \%) & Clinical LN (n, \%) & $\operatorname{RAI}(n, \%)$ & FU (years) & TR (n, \%) & LNR (n, \%) \\
\hline Wada et al. (53) & Japan & 259 & $\mathrm{~N} / \mathrm{A}$ & $24(9.3)$ & $\mathrm{N} / \mathrm{A}$ & 5.1 & $6(2.3)$ & $5(1.9)$ \\
\hline Pelizzo et al. (54) & Italy & 403 & $\mathrm{~N} / \mathrm{A}$ & $\mathrm{N} / \mathrm{A}$ & $260(60.5)$ & 8.5 & $6(1.5)$ & $1(0.2)$ \\
\hline Besic et al. (56) & Slovenia & 254 & $\mathrm{~N} / \mathrm{A}$ & $51(20.1)$ & $124(49)$ & 4.7 & $7(2.7)$ & $6(2.4)$ \\
\hline Mercante et al. (57) & Italy & 445 & $\mathrm{~N} / \mathrm{A}$ & $37(8.3)$ & $389(87.4)$ & 5.3 & $17(3.8)$ & $13(2.9)$ \\
\hline Londero et al. (60) & Denmark & 406 & $\mathrm{~N} / \mathrm{A}$ & $\mathrm{N} / \mathrm{A}$ & $161(40)$ & 8 & $15(3.7)$ & $7(1.7)$ \\
\hline Lee et al. (61) & South Korea & 2014 & $18(0.9)$ & $\mathrm{N} / \mathrm{A}$ & $51(2.5)$ & 11.2 & 126(6.3) & $98(4.9)$ \\
\hline Gschwandtner et al. (62) & Austria & 1391 & $\mathrm{~N} / \mathrm{A}$ & $\mathrm{N} / \mathrm{A}$ & $255(18.3)$ & 7 & $5(0.4)$ & $5(0.4)$ \\
\hline Kim et al. (63) & South Korea & 5656 & $210(3.7)$ & N/A & $\mathrm{N} / \mathrm{A}$ & 5.1 & 126(2.2) & 122(2.2) \\
\hline Cecoli et al. (64) & Italy & 437 & 0 & 0 & $152(38.7)$ & 5.8 & $6(1.4)$ & $3(0.7)$ \\
\hline
\end{tabular}

ETE, extrathyroidal extension; LN, Iymph node; RAl, radioactive iodine; FU, follow up; TR, total recurrence; LNR, lymph node recurrence; N/A, not available.

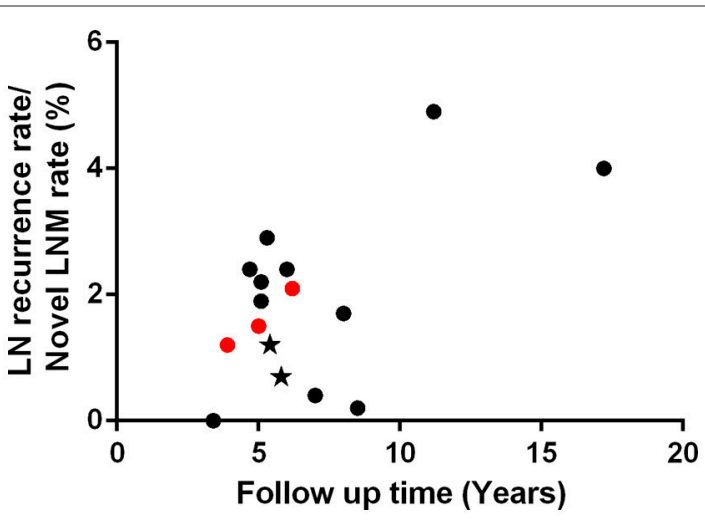

FIGURE 2 | Cervical lymph node recurrence rates (black dots and stars) among 13 different PTMC cohorts and novel LNM rates (red dots) in AS groups. With <10-year follow up, 5 PTMC cohorts had relatively higher lymph node recurrence than novel LNM rate in AS patients because all of these 5 cohorts had small group of PTMC with gross ETE and/or clinical apparent lymph node (detail seen Table 5). The lymph node recurrence rates of "low-risk" cohorts (black stars), which excluded patients with gross ETE and clinical apparent lymph node, were relatively less than novel LNM rates in AS groups.

decrease recurrence risk in contralateral lobe and neck lymph node. (3) Serum Tg is an accurate and reliable biomarker of tumor burden in Tg auto-antibody negative patients who received a total thyroidectomy. (4) For PTMC patients with lymph node recurrence, metastatic lymph nodes were stable for many years (89). At this time, it may be more feasible to use serum Tg levels during AS for monitoring recurrent lymph nodes.

\section{ETHICAL ISSUES}

In 2000, Emanuel et al. argued the most important ethical concerns in clinical trials was "the potential benefits to individuals must outweigh the risks (90).” However, with only
US and FNA, we have little prognostic information, with the exception of age and tumor size, to evaluate the safety of AS. Consequently, Stack and Angelos recommended implementing only institutional review board-approved research protocols or surveillance contracts for educating patients, codifying the relationship between clinician and patient, and establishing medicolegal protections (91). But Morris et al. disagreed, instead believing these documents would jeopardize patient autonomy and influence their choice (92). Supporters of AS think higher risk among a small number of patients will and should be balanced by the advantage of avoiding surgery in a larger number of patients (93). However, is it ethical to risk the health of some patients, even a minority, for the greater good? Recently, Dr. Akira estimated the lifetime disease progression probabilities, stratified by patient age, of PTMC during AS, which were $60.3 \%$ (20 s), 37.1\% (30s), 27.3\% (40 s), 14.9\% (50s), 9.9\% (60s), and $3.5 \%$ (70 s) (87). This study provided significant information for AS patients selection. In the future, we need more information from imaging and molecular signatures to provide more accurate risk stratifications of the clinical behavior and the risk for disease progression of PTMC patients during AS.

\section{IMPROVEMENTS IN IMAGING}

\section{US}

In terms of diagnostic accuracy, 3-dimensional (3D) US outperformed 2-dimensional (2D) US when compared to patients' final histopathological outcome (94). A single sweep of $3 \mathrm{D}$ US provided imaging for reconstruction and overcame the major limitations of 2D US. Kim et al. evaluated 91 thyroid nodules from 85 consecutive patients and compared sensitivity and specificity between $3 \mathrm{D}$ and 2D US. They found 3D US had significantly higher sensitivities than 2D in predicting ETE (94). In contrast, a separate study from South Korea reported 3D US with tomographic ultrasound imaging algorithms alone was not superior to real-time 2D US (95). This discrepancy is perhaps attributable to the differences that variable image reconstruction 
parameters have on US interpretation. Slapa et al. summarized the advantages of 3D US as follows: distinct separation between imaging acquisition and analysis, better remote consultation, less operator dependency, and increased diagnostic accuracy (96).

Recently, shear wave elastography (SWE) has emerged to diagnose and predict the pathologic prognostic factors of PTC using quantitative information about thyroid nodule elasticity. It is operator-independent and can display elastograms of estimated tissue stiffness. Yun et al. enrolled 208 PTC patients and found ETE was associated with the elasticity index determined by SWE, and quantification of the elasticity index could accurately predict pathologic ETE (97). Diagnostic accuracy of cervical lymph nodes was also significantly improved by SWE. Woo et al. reported the elasticity indices of SWE were significantly correlated with not only malignant lymph nodes, but also the number, size and ETE of involved lymph nodes. They concluded quantitative SWE could predict pathologic prognostic factors of cervical LNM (98). Azizi et al. evaluated 270 lymph nodes from 236 patients with both conventional US and SWE. Using single shear wave velocity cut off of $2.93 \mathrm{~m} / \mathrm{s}$, SWE could improve diagnostic sensitivity and specificity to 92.59 and $75.46 \%$, respectively. Lymph node stiffness measured by SWE is reported to be an independent predictor of malignant lymph node (99). Xu from China also found predictive performance for CLNM in PTC was markedly improved with the combination of conventional US and SWE, which indicated SWE would be a useful tool for treatment planning (100).

\section{CT and MRI}

Liu et al. evaluated cervical metastatic lymph nodes using dual-energy spectral CT and found venous phase $\lambda_{\mathrm{HU}}$ (slope of the spectral Hounsfield unit curve) was the best parameter for diagnosis with sensitivity, specificity of 62.0 and $91.1 \%$, respectively. Compared to conventional CT, quantitative assessment with gemstone spectral CT parameters improved accuracy for detecting cervical metastatic lymph nodes of PTC (101). Considering MRI, several studies have reported the apparent diffusion coefficient (ADC) derived from diffusionweighted imaging (DWI) could be used as a predictor for thyroid cancer aggressiveness (102-104). Hao et al. evaluated the predictive performance of ADC for ETE of PTCs in a cohort of 23 PTMC patients. PTCs with ETE had significant lower median $\mathrm{ADC}$, 5th percentile $\mathrm{ADC}$, and 25th percentile ADC while PTMCs had significant lower ADC only in 5th percentile ADC (102). Another study used DWI histogram analysis of whole tumor ADC to investigate the relationships between ADC parameters with histopathological features like LNM, ETE, Ki-67, and p53. They found ADC mean, ADC max, ADC median, ADC modus, ADC p75, and ADC p90 were all related significantly with $\mathrm{p} 53$, which was prognostic marker for thyroid cancer. Moreover, they identified an inverse correlation between ADC max, ADC p90, and Ki-67, which was regarded as predictor for disease progression during AS (105). Importantly, ADC histogram skewness and kurtosis were also identified to be parameters for predicting LNM (104). Meyer et al. demonstrated MRI texture analysis, which was a novel imaging technique derived from extensive data provided by conventional sequences, was a very useful tool to predict histopathological features in thyroid cancer although they only enrolled 13 thyroid cancer patients (4 PTC; 4FTC; and 5 ATC) (103).

\section{IMPROVEMENTS IN BIOMARKER}

\section{BRAF}

Braf, as a member of RAF kinase family, served as a growth signal transduction protein kinase. Braf ${ }^{\mathrm{V} 600 \mathrm{E}}$ composed nearly $90 \%$ of all somatic mutated Braf and played an important oncogenic role in thyroid tumorigenesis (106). The replacement of valine with glutamate at codon 600 resulted from the substitution of thymine with adenine at nucleotide 1799, then activated its serine/threonine kinase constitutively, leading to further activation of MAPK pathway (107). The downstream effectors of mutated Braf, such as Mek and Erk, will be phosphorylated and take part in thyroid tumorigenesis $(106,107)$. Moreover, Braf $^{\mathrm{V} 600 \mathrm{E}}$ could promote tumor formation and aggressiveness by regulating the expression of other genes epigenetically, either through hyper- or hypomethylation. The interaction between Braf $^{\mathrm{V} 600 \mathrm{E}}$ and epigenetic alterations, which downregulated tumor suppressor genes (like T1MP3, SLC5A8, DAPK1, RAR $\beta 2$ ) and upregulated oncogenes (like HMGB2 and FDG1), increased tumor cell proliferation and invasion $(108,109)$.

In 2015, a meta-analysis was performed to investigate the correlation between Braf $^{\mathrm{V} 600 \mathrm{E}}$ and clinical features for PTMC (110). In Li et al, the authors analyzed 3437 PTMC patients across 19 studies after searching PubMed, EMBASE, and the Cochrane library. They found that $\mathrm{Braf}^{\mathrm{V} 600 \mathrm{E}}$ mutation was associated with aggressive clinicopathological features like multifocality, ETE, LNM, and advanced stage of PTMC. Consequently, they suggested $\mathrm{Braf}^{\mathrm{V} 600 \mathrm{E}}$ could be used as a risk factor for the stratification and management of PTMC (110). Lee et al. predicted gross ETE of PTMC with 100\% sensitivity through the use of tumor size, US features, and $\mathrm{Braf}^{\mathrm{V} 600 \mathrm{E}}$ mutation status. They categorized US features of the primary tumor into four groups: A: intraparechymal; B, tumor abutting the capsule $<50 \%$ of diameter; C: tumor abutting $>50 \%$ of diameter; and $\mathrm{D}$ : tumor destroyed the capsule. In a subgroup of Braf ${ }^{\mathrm{V} 600 \mathrm{E}}$ negative patients, a tumor size of $0.7 \mathrm{~cm}$ and US categorizations $\mathrm{B}$ and $\mathrm{C}$ were cut-off values for gross ETE, with $100 \%$ sensitivity, whereas US categorizations A and B as cutoff value had $100 \%$ sensitivity for predicting gross ETE in the $\mathrm{Braf}^{\mathrm{V} 600 \mathrm{E}}$ mutation positive patients (111). Besides clinical risk features, Chen et al. also found PTMCs with $\mathrm{Braf}^{\mathrm{V} 600 \mathrm{E}}$ mutation were more likely to recur (OR 2.09 [95\% CI:1.31-3.33]) by a meta-analysis of 2,247 PTMC patients from 4 published studies and 2 institutional cohort primary data (112). Niemeier et al. developed a molecular-pathological score (including superficial tumor location, intraglandular tumor spread/multifocality, tumor fibrosis, and Braf status) to stratify PTMC into different risk groups and successfully predict recurrence rate. In the diagnosis of aggressive PTMC, the combination of histologic features and Braf status increased diagnostic sensitivity from 77 to $96 \%$ and specificity from 68 to $80 \%$ (113). With mounting evidence, revisions to the ATA guidelines in 2015 began to consider Braf ${ }^{\mathrm{v} 600 \mathrm{e}}$ status as a risk 
factor of structural disease recurrence in PTMC patients after initial therapy (25).

However, Miyauchi et al. in the Kuma hospital detected $\mathrm{BRAF}^{\mathrm{V} 600 \mathrm{E}}$ status in 11 PTMC patients without disease progression, 10 PTMC with tumor size progression, and 5 with novel LNM. The percentage of $\mathrm{Braf}^{\mathrm{V} 600 \mathrm{E}}$ was 64, 70, and $80 \%$ in each group, respectively (114). Consequently, the use of $\mathrm{BRAF}^{\mathrm{V} 600 \mathrm{E}}$ alone is insufficient to accurately stratify risk in PTMC patients. If using $\mathrm{Braf}^{\mathrm{V} 600 \mathrm{E}}$ alone as biomarker for selecting AS candidates, nearly $60 \%$ of PTMCs who may never have disease progression will be categorized wrongly. Considering high prevalence of $\mathrm{Braf}^{\mathrm{v}}{ }^{600 \mathrm{e}}$ mutation among PTMC, Braf ${ }^{\mathrm{V} 600 \mathrm{E}}$ alone cannot be used as reliable biomarker for differentiating aggressive PTMC from indolent ones, and identifying potential disease progression cases from stable ones during AS. A possible reason may be that the oncogenic event driving PTMC aggressiveness requires additional mutations acting in conjunction with $\mathrm{BRAF}^{\mathrm{V} 600 \mathrm{E}}$ and the MAPK signaling pathway (115). Thus, the identification of additional genetic variants, which are less abundant than $\mathrm{BRAF}^{\mathrm{V} 600 \mathrm{E}}$, could be important in predicting PTMC aggressiveness.

\section{TERT}

Telomerase reverse transcriptase (TERT) is the catalytic protein subunit of telomerase, which can maintain chromosomal integrity and genome stability (116). Malignant cancer cells, which were replicative immortal, required activation of telomerase and regulation of other growth controlling genes, pathways and molecular by TERT (117). First reported in 2013, TERT promoter mutation (C228T and C250T) in thyroid cancer has progressed rapidly in recent 5 years (118). Many studies have demonstrated TERT mutation was associated with more aggressive clinicopathological features of thyroid cancer, such as male gender, ETE, LNM, advanced stage, distant metastasis, recurrence, and mortality (119-122). Two meta-analyses in 2016 investigated clinicopathological significance of TERT promoter mutations in PTC and found the average prevalence of TERT promoter mutation was around $10 \%$. Additionally, PTC patients with TERT promoter mutation displayed more aggressive histopathological features $(121,122)$. Kim et al. developed an effective risk stratification system using TERT promoter mutation status that reliably predicted structural recurrence and mortality in DTC patients (119).

Of note, the co-occurrence of Braf and TERT promoter mutations enhanced the predictive ability for prognosis of PTC. Moon et al. performed a meta-analysis including 13 studies with 4,347 PTC patients and found the co-occurrence of Braf and TERT promoter mutations was more significantly associated with aggressive clinicopathological features than either mutation alone (123). Accordingly, they believed these two mutations had a synergistic effect on prognosis and were useful in risk stratification of PTC. Liu et al. categorized 1,051 PTC patients according to mutation status of Braf and TERT promoter and demonstrated deaths per 1,000-person years in PTC patients with neither mutation, $\mathrm{Braf}{ }^{\mathrm{V} 600 \mathrm{E}}$ alone, TERT mutation alone, or both mutations were $0.80,3.08,6.62$, and 29.86, respectively. Simple 4-genotype classification can predict disease-specific mortality accurately (124). Recently, this synergistic effect of BRAF and TERT promoter has been demonstrated as $\mathrm{Braf}^{\mathrm{V} 600 \mathrm{E}} \rightarrow$ MAPK pathway $\rightarrow$ FOS $\rightarrow$ GABP $\rightarrow$ TERT signaling/transcription axis in human cancers (125). Firstly, mutated $\mathrm{Braf}^{\mathrm{V} 600 \mathrm{E}}$ activated MAPK pathway, which phosphorylated FOS to be an active transcription factor for activating the GABPB promotor. Then increased expression of GABPB and formation of GABPAGABPB complex activated the mutant TERT promoter. In this axis, phosphorylated FOS played important oncogenic bridging role between $\mathrm{Braf}^{\mathrm{V} 600 \mathrm{E}}$ and TERT promoter mutations (125).

However, de Biase et al. detected TERT promoter mutations with next-generation sequencing in 431 PTMC patients assembled from six different institutions. They found the prevalence of TERT promoter mutations among PTMC was only $4.7 \%$, less than the $10 \%$ reported in PTC patients. Moreover, the presence of TERT promoter mutations was not associated with unfavorable clinicopathological features (126). Also in Miyauchi's study, no PTMC patients undergoing AS were positive for TERT promoter mutations, even in a subgroup of patients with increased tumor sizes and/or novel lymph node appearance (114). Therefore, with regard to its low prevalence in PTMC, TERT promoter mutations are unlikely to be reliable molecular markers of tumor aggressiveness/progression.

\section{MicroRNA}

MicroRNA is defined as a group of small endogenous, single stranded non-coding RNAs of 19-25 nucleotides that can exclusively regulate their proprietary mRNA expression (127). The miRNA-221-222 cluster, downstream of the MAPK pathway, played an important role in tumorigenesis and aggressiveness for PTC (128). Located on the X chromosome, miRNA221-222 cluster was regulating PTC formation and invasion through negative regulation of p27 (129). Multiple studies have demonstrated that upregulated miR-221-222 cluster was associated with more unfavorable clinicopathological features, treatment resistance, increased recurrence rate, and worse prognosis (130-133). Because of that, the miRNA-221-222 cluster was considered as a potential biomarker for aggressive PTC. Additionally, miRNA-146b is another well-studied and overexpressed microRNA in PTC. Its expression level was positively associated with tumor aggressiveness and poor prognosis $(131,133)$. Study has shown miRNA-146b functioned in PTC through binding with the $3^{\prime}$ UTR region of retinoic acid receptor beta (RAR $\beta$ ) (134). Moreover, advanced PTC patients could receive benefit from retinoic acid (a RAR $\beta$ ligand) treatment. Retinoic acid treatment resulted in tumor shrinkage and increased radioiodine uptake in $38 \%$ and $26 \%$ of patients, respectively (135). These studies suggested that miRNA-146b might play important role in thyroid cancer initiation and progression. In addition to the two microRNAs discussed above, there are also other microRNAs which have been identified to be associated with tumor aggressiveness (especially ETE, LNM and distant metastasis) including miRNA135-b, 146-a, 146-5p and several others (Table 6) $(129,136-155)$.

The upregulation of miRNA-221-222 cluster and miRNA$146 \mathrm{~b}$ in $\mathrm{BRAF}^{\mathrm{V} 600 \mathrm{E}}$ positive tumors, was suggested to be attributable to activation via the NF- $\kappa B$ pathway $(156,157)$. In 
TABLE 6 | Tissue microRNA as predictor for aggressiveness in papillary thyroid carcinoma.

\begin{tabular}{|c|c|c|c|c|c|c|}
\hline MicroRNA & $\begin{array}{l}\text { Change } \\
\text { in APTC }\end{array}$ & ETE & LNM & DM & Target molecular & References \\
\hline MiR-126-3p & $\downarrow$ & * & & & ADAM9,SLC7A5 & $(136)$ \\
\hline MiR-130b & $\downarrow$ & * & & & N/D & $(137)$ \\
\hline MiR-135b & $\uparrow$ & * & & & $\mathrm{N} / \mathrm{D}$ & $(138)$ \\
\hline MiR-146a & $\uparrow$ & * & * & & RAR $\beta, P R K C E$ & $\begin{array}{l}(137,139- \\
142)\end{array}$ \\
\hline MiR-146b & $\uparrow$ & * & * & * & $\begin{array}{l}\text { KIT, SMAD4, } \\
\text { ZNRF3,IRAK1, } \\
\text { RAR } \beta\end{array}$ & $\begin{array}{l}(137-140 \\
142-148)\end{array}$ \\
\hline MiR-16 & $\downarrow$ & * & & & ITGA2 & $(145)$ \\
\hline MiR-199b-5p & $\uparrow$ & * & $\star *$ & & $\mathrm{~N} / \mathrm{D}$ & $(149)$ \\
\hline MiR-221 & $\uparrow$ & * & * & * & p27,TIMP3 & $\begin{array}{l}(129,132, \\
137,138, \\
143,145 \\
150)\end{array}$ \\
\hline MiR-222 & $\uparrow$ & * & * & & $\begin{array}{l}\text { p27, } \\
\text { PPP2R2A, TIMP3 }\end{array}$ & $\begin{array}{l}(129,132, \\
137,138, \\
143,145 \\
151)\end{array}$ \\
\hline MiR-2861 & $\uparrow$ & & $\star \star$ & & $\mathrm{N} / \mathrm{D}$ & $(152)$ \\
\hline MiR-30a-3p & $\downarrow$ & & * & & $\mathrm{N} / \mathrm{D}$ & $(149)$ \\
\hline MiR-34b & $\downarrow$ & * & & & $\mathrm{N} / \mathrm{D}$ & $(137)$ \\
\hline MiR-363-3p & $\downarrow$ & & * & & PIK3CA & (153) \\
\hline MiR-451 & $\uparrow$ & & $\star *$ & & $\mathrm{~N} / \mathrm{D}$ & $(152)$ \\
\hline MiR-613 & $\downarrow$ & * & & & FN1 & $(145)$ \\
\hline MiR-622 & $\downarrow$ & & * & & VEGFA & $(154)$ \\
\hline
\end{tabular}

APTC, aggressive papillary thyroid carcinoma; ETE, extrathyroidal extension; LNM, lymph node metastases; DM, distant metastases; N/D, not determinated. $\uparrow$, up-regulated in aggressive PTC. $\downarrow$, down-regulated in aggressive PTC. ${ }^{*}$, related with aggressive features, ${ }^{\star *}$ Related with central and lateral neck lymph node metastases.

Braf $^{\mathrm{V} 600 \mathrm{E}}$ PTMC patients, it remains unknown what molecular events trigger disease progression during AS. Would it be possible to increase our ability to predict PTMC disease progression by screening FNA biopsies for clinically actionable somatic mutations and/or the expression of miRNAs?

\section{Serum Circulating Biomarkers}

Compared with inherent instability of mRNA, circulating miRNA is subjected to nuclease activity and resistant to environment. Because of that, miRNA, which can be readily detected in bloodstream, is believed as a potential ideal candidate serum biomarker for PTC (158). Yu et al. detected serum miRNA expression by Solexa sequencing and found increased miR-151-5p, detected in the serum, was associated with LNM of PTC (159). However, the evidence of using circulating miRNA to predict disease progression of PTMC during AS was absent. In addition, a prospective observational pilot study found circulating myeloid-derived suppressor cells, which were detected preoperatively by novel flow cytometrybased immunoassay, were positively associated with a higher TNM stage and disease recurrence (160). Lubitz et al. reported they only detected $63 \%$ circulating Braf $^{\mathrm{V} 600 \mathrm{E}}$ mutation by novel RNA-based blood assay compared with conventional
TABLE 7 | Long Non-coding RNA as predictor for aggressiveness in papillary thyroid carcinoma.

\begin{tabular}{|c|c|c|c|c|c|c|}
\hline LncRNA & $\begin{array}{l}\text { Change } \\
\text { in APTC }\end{array}$ & ETE & LNM & DM & Target molecular & References \\
\hline ATB & $\uparrow$ & & * & & $\mathrm{N} / \mathrm{D}$ & $(167)$ \\
\hline CASC2 & $\downarrow$ & & * & & $N / D$ & $(168)$ \\
\hline CNALPTC1 & $\uparrow$ & & * & & miR-30 family & $(169)$ \\
\hline GAS8-AS1 & $\uparrow$ & & * & & N/D & $(170)$ \\
\hline HIT000218960 & $\uparrow$ & & * & & HMGA2 & $(165)$ \\
\hline HOXD-AS1 & $\uparrow$ & & * & * & $N / D$ & $(171)$ \\
\hline LINC00271 & $\downarrow$ & * & * & & N/D & $(166)$ \\
\hline LINC01061 & $\uparrow$ & & * & & $\mathrm{miR}-4316$ & $(172)$ \\
\hline LOC100507661 & $\uparrow$ & & * & & N/D & $(163)$ \\
\hline MALAT1 & $\uparrow$ & & * & & $\mathrm{N} / \mathrm{D}$ & $(173)$ \\
\hline MEG3 & $\downarrow$ & & * & & Rac1 & $(174)$ \\
\hline NONHSAT037832 & $\downarrow$ & & * & & N/D & $(175)$ \\
\hline NONHSAT076754 & $\uparrow$ & & * & & $N / D$ & $(176)$ \\
\hline NONHSAT129183 & $\uparrow$ & & * & & $\mathrm{N} / \mathrm{D}$ & $(177)$ \\
\hline NONHSAT076747 & $\uparrow$ & & * & & $N / D$ & $(178)$ \\
\hline NONHSAT122730 & $\uparrow$ & & * & & N/D & $(178)$ \\
\hline NR_036575.1 & $\uparrow$ & * & & & N/D & $(179)$ \\
\hline PVT1 & $\uparrow$ & * & * & & IGF1R & $(180)$ \\
\hline RP11-402L6.1 & $\uparrow$ & & * & & N/D & $(181)$ \\
\hline XLOC_051122 & $\uparrow$ & & * & & N/D & (182) \\
\hline XLOC_006074 & $\uparrow$ & & * & & N/D & (182) \\
\hline
\end{tabular}

APTC, aggressive papillary thyroid carcinoma; ETE, extrathyroidal extension; LNM, lymph node metastases; DM, distant metastases; N/D, not determinated. $\uparrow$, up-regulated in aggressive PTC. $\downarrow$, down-regulated in aggressive PTC. * , related with aggressive features.

tissue assays on surgical specimens. They concluded detecting circulating $\mathrm{Braf}^{\mathrm{V} 600 \mathrm{E}}$ could be a surrogate for conventional FNA detection (161). In contrast, a separate study found only $37.3 \%$ of PTC patients with locally advanced and metastasis were detected to have circulating Braf ${ }^{\mathrm{V} 600 \mathrm{E}}$ mutation. These patients didn't get any benefits from analysis of circulating tumor DNA (162). Accordingly, there are several challenges about the application of serum circulating biomarkers for PTMC which include: (1) Molecular FNA diagnostics with biomarkers have high concordance with pathological results. In contrast, serum circulating biomarkers demonstrate only partial concordance with FNA determined pathology. Consequently, circulating biomarkers from blood are not superior to FNA biopsies in predicting aggressiveness. (2) All studies about detecting serum circulating biomarkers enrolled cancer patients with advanced stage or distant metastasis. However, the serum circulating biomarkers identified in high-risk patients may not be detectable in low-risk PTMC patients. (3) Genetic background and alternations in circulating cells may be different with those in the primary tumor. Some cancer cells derived from the primary tumor may undergo changes that facilitate blood vessel invasion and then turn to circulating cells. (4) Other malignant tumors shared the same circulating miRNA or DNA with thyroid cancer. Differentiating where these circulating biomarkers came from is difficult. 


\section{Other Novel Targets}

Besides genetic alternations, LncRNAs, which is defined as a class of RNAs containing over 200 nucleotides, play important roles in tumor progression (163). Kim et al. reported LOC100507661 expression was positively related with LNM and Braf ${ }^{\mathrm{V} 600 \mathrm{E}}$ mutation in PTC patients (164). High expression of HOTAIR in thyroid cancer was associated with larger tumor size, more metastatic lymph nodes, and poorer outcome after a meta-analysis of TCGA and GEO databases (165). PTC patients with high expression of HIT000218960 had more multifocality, LNM and advanced TNM stage (166). Downregulation of LINC00271 was identified as an independent risk factor for ETE, LNM, TNM stage and recurrence (167). Other LncRNAs, which related with aggressiveness of PTC, were also identified and summarized in Table 7 (164, 166183).

Epigenetic changes, particularly methylation of DAPK, REC8, TIMP3, CDH1, FGFR2 were also reported to be associated with aggressive behavior of PTC (184). Whether we can predict the aggressiveness of PTMC using these biomarkers derived from PTC patients remains to be investigated.

\section{REFERENCES}

1. Klotz L. Cancer overdiagnosis and overtreatment. Curr Opin Urol. (2012) 22:203-9. doi: 10.1097/MOU.0b013e32835259aa

2. Esserman LJ, Thompson IM Jr, Reid B. Overdiagnosis and overtreatment in cancer: an opportunity for improvement. JAMA (2013) 310:797-8. doi: 10.1001/jama.2013.108415

3. Welch HG, Black WC. Overdiagnosis in cancer. J Natl Cancer Inst. (2010) 102:605-13. doi: 10.1093/jnci/djq099

4. Harach HR, Franssila KO, Wasenius VM. Occult papillary carcinoma of the thyroid. A "normal" finding in Finland. A systematic autopsy study. Cancer (1985) 56:531-8. doi: 10.1002/1097-0142(19850801)56:3<531::AIDCNCR2820560321>3.0.CO;2-3

5. Kovács GL, Gonda G, Vadasz G, Ludmany E, Uhrin K. Epidemiology of thyroid microcarcinoma found in autopsy series conducted in areas of different iodine intake. Thyroid (2005) 15:152-7. doi: 10.1089/thy.2005.15.152

6. Martinez-Tello FJ, Martinezcabruja R, Fernandezmartin J, Lassooria C, Ballestincarcavilla C. Occult carcinoma of the thyroid. A systematic autopsy study from Spain of two series performed with two different methods. Cancer (1993) 71:4022-9. doi: 10.1002/1097-0142(19930615)71:12<4022::AIDCNCR2820711236>3.0.CO;2-O

7. Stamatiou K, Alevizos A, Agapitos E, Sofras F. Incidence of impalpable carcinoma of the prostate and of non-malignant and precarcinomatous lesions in Greek male population: an autopsy study. Prostate (2006) 66:131928. doi: 10.1002 /pros.20339

8. Welch HG, Black WC. Using autopsy series to estimate the disease "reservoir" for ductal carcinoma in situ of the breast: how much more breast cancer can we find? Ann Intern Med. (1997) 127:1023-8. doi: 10.7326/0003-4819-127-11-199712010-00014

9. Yamamoto Y, Maeda T, Izumi K, Otsuka H. Occult papillary carcinoma of the thyroid. A study of 408 autopsy cases. Cancer (1990) 65:1173-9. doi: 10. 1002/1097-0142(19900301)65:5<1173::AID-CNCR2820650524>3.0.CO;2-2

10. Haymart MR, Miller DC, Hawley ST. Active surveillance for low-risk cancers - a viable solution to overtreatment? N Engl J Med. (2017) 377:203-6. doi: 10.1056/NEJMp1703787

11. Bul M, Zhu X, Valdagni R, Pickles T, Kakehi Y, Rannikko A, et al. Active surveillance for low-risk prostate cancer worldwide: the PRIAS study. Eur Urol. (2013) 63:597-603. doi: 10.1016/j.eururo.2012.11.005

\section{CONCLUSION}

The utility of AS for low-risk PTMC patients requires improvements our abilities to accurate and confidently stratify patient risk. Due to the substantially improved diagnostic performance in identifying gross ETE and macroscopic cervical LNM, the combined use of US and CT imaging modalities is strongly recommended for use in AS. Patients should be informed and educated fairly and objectively according to the data that is currently available. Dynamic monitoring, risk stratification, and personal follow-up schedules are tantamount in minimizing the potential risks incurred by recommending patients against immediate surgery. Furthermore, the advent of increasingly sophisticated imaging technologies, and the screening for novel prognostic biomarkers have shown great promise, although future validation studies are warranted.

\section{AUTHOR CONTRIBUTIONS}

All authors listed have made a substantial, direct and intellectual contribution to the work, and approved it for publication.

12. Tosoian JJ, Carter HB, Lepor A, Loeb S. Active surveillance for prostate cancer: current evidence and contemporary state of practice. Nat Rev Urol. (2016) 13:205-15. doi: 10.1038/nrurol.2016.45

13. Welty CJ, Cowan JE, Nguyen H, Shinohara K, Perez N, Greene KL, et al. Extended followup and risk factors for disease reclassification in a large active surveillance cohort for localized prostate cancer. J Urol. (2015) 193:807-11. doi: 10.1016/j.juro.2014.09.094

14. Hamdy FC, Donovan JL, Lane JA, Mason M, Metcalfe C, Holding $\mathrm{P}$, et al. 10-year outcomes after monitoring, surgery, or radiotherapy for localized prostate cancer. $N$ Engl J Med. (2016) 375:1415-24. doi: 10.1056/NEJMoa1606220

15. Miyauchi $\mathrm{A}$, Ito $\mathrm{Y}$, Oda $\mathrm{H}$. Insights into the management of papillary microcarcinoma of the thyroid. Thyroid (2018) 28:23-31. doi: 10.1089/thy.2017.0227

16. Ito Y, Miyauchi A, Kudo T, Oda H, Yamamoto M, Sasai H, et al. Trends in the implementation of active surveillance for low-risk papillary thyroid microcarcinomas at Kuma Hospital: gradual increase and heterogeneity in the acceptance of this new management option. Thyroid (2018) 28:488-95. doi: 10.1089/thy.2017.0448

17. Leboulleux S, Tuttle RM, Pacini F, Schlumberger M. Papillary thyroid microcarcinoma: time to shift from surgery to active surveillance? Lancet Diabetes Endocrinol. (2016) 4:933-42. doi: 10.1016/s2213-8587(16)30 180-2

18. Nickel B, Brito JP, Barratt A, Jordan S, Moynihan R, McCaffery K. Clinicians' views on management and terminology for papillary thyroid microcarcinoma: a qualitative study. Thyroid (2017) 27:661-71. doi: 10.1089/thy.2016.0483

19. Chow SM, Law SC, Chan JK, Au SK, Yau S, Lau WH. Papillary microcarcinoma of the thyroid-Prognostic significance of lymph node metastasis and multifocality. Cancer (2003) 98:31-40. doi: $10.1002 / \mathrm{cncr} .11442$

20. Pyo JS, Sohn JH, Kang G. Detection of tumor multifocality is important for prediction of tumor recurrence in papillary thyroid microcarcinoma: a retrospective study and meta-analysis. J Pathol Transl Med. (2016) 50:27886. doi: 10.4132/jptm.2016.03.29

21. Riss JC, Peyrottes I, Chamorey E, Haudebourg J, Sudaka A, Benisvy D, et al. Prognostic impact of tumour multifocality in thyroid papillary microcarcinoma based on a series of 160 cases. Eur Ann Otorhinolaryngol Head Neck Dis. (2012) 129:175-8. doi: 10.1016/j.anorl.2011.11.003 
22. So YK, Kim MW, Son YI. Multifocality and bilaterality of papillary thyroid microcarcinoma. Clin Exp Otorhinolaryngol. (2015) 8:174-8. doi: 10.3342/ceo.2015.8.2.174

23. Zhao Q, Ming J, Liu C, Shi L, Xu X, Nie X, et al. Multifocality and total tumor diameter predict central neck lymph node metastases in papillary thyroid microcarcinoma. Ann Surg Oncol. (2013) 20:746-52. doi: 10.1245/s10434-012-2654-2

24. Diker-Cohen T, Hirsch D, Shimon I, Bachar G, Akirov A, Duskin-Bitan H, et al. Impact of minimal extra-thyroid extension in differentiated thyroid cancer: systematic review and meta-analysis. J Clin Endocrinol Metab. (2018) 103:2100-6. doi: 10.1210/jc.2018-00081

25. Haugen BR, Alexander EK, Bible KC, Doherty GM, Mandel SJ, Nikiforov YE, et al. 2015 American Thyroid Association Management Guidelines for adult patients with thyroid nodules and differentiated thyroid cancer: The American Thyroid Association Guidelines Task Force on thyroid nodules and differentiated thyroid cancer. Thyroid (2016) 26:1-133. doi: $10.1089 /$ thy. 2015.0020

26. Shimamoto K, Satake H, Sawaki A, Ishigaki T, Funahashi H. Preoperative staging of thyroid papillary carcinoma with ultrasonography. Eur J Radiol. (1998) 29:4-10. doi: 10.1016/S0720-048X(97)00184-8

27. Tomoda C, Uruno T, Takamura Y, Ito Y, Miya A, Kobayashi $\mathrm{K}$, et al. Ultrasonography as a method of screening for tracheal invasion by papillary thyroid cancer. Surg Today (2005) 35:819-22. doi: 10.1007/s00595-005-3037-0

28. Kwak JY, Kim E-K, Youk JH, Kim MJ, Son EJ. Extrathyroid extension of well-differentiated papillary thyroid microcarcinoma on US. Thyroid (2008) 18:609-14. doi: 10.1089/thy.2007.0345

29. Kim H, Kim JA, Son EJ, Youk JH, Chung TS, Park CS, et al. Preoperative prediction of the extrathyroidal extension of papillary thyroid carcinoma with ultrasonography versus MRI: a retrospective cohort study. Int J Surg. (2014) 12:544-8. doi: 10.1016/j.ijsu.2014.03.003

30. Lee CY, Kim SJ, Ko KR, Chung KW, Lee JH. Predictive factors for extrathyroidal extension of papillary thyroid carcinoma based on preoperative sonography. J Ultrasound Med. (2014) 33:231-8. doi: 10.7863/ultra.33.2.231

31. Lee DY, Kwon TK, Sung MW, Kim KH, Hah JH. Prediction of extrathyroidal extension using ultrasonography and computed tomography. Int J Endocrinol. (2014) 2014:351058. doi: 10.1155/2014/351058

32. Moon SJ, Kim DW, Kim SJ, Ha TK, Park HK. Ultrasound assessment of degrees of extrathyroidal extension in papillary thyroid microcarcinoma. Endocr Practice (2014) 20:1037-43. doi: 10.4158/EP14016.OR

33. Kamaya A, Tahvildari AM, Patel BN, Willmann JK, Jeffrey RB, Desser TS. Sonographic detection of extracapsular extension in papillary thyroid cancer. J Ultrasound Med. (2015) 34:2225-30. doi: 10.7863/ultra.15.02006

34. King AD, Ahuja AT, To EW, Tse GM, Metreweli C. Staging papillary carcinoma of the thyroid: magnetic resonance imaging vs ultrasound of the neck. Clin Radiol. (2000) 55:222-6. doi: 10.1053/crad.1999.0373

35. Choi JS, Kim J, Kwak JY, Kim MJ, Chang HS, Kim EK. Preoperative staging of papillary thyroid carcinoma: comparison of ultrasound imaging and CT. AJR Am J Roentgenol. (2009) 193:871-8. doi: 10.2214/AJR.09.2386

36. Park JS, Son KR, Na DG, Kim E, Kim S. Performance of preoperative sonographic staging of papillary thyroid carcinoma based on the sixth edition of the AJCC/UICC TNM classification system. AJR Am J Roentgenol. (2009) 192:66-72. doi: 10.2214/AJR.07.3731

37. Choi JS, Chung WY, Kwak JY, Moon HJ, Kim MJ, Kim EK. Staging of papillary thyroid carcinoma with ultrasonography: performance in a large series. Ann Surg Oncol. (2011) 18:3572-8. doi: 10.1245/s10434-0111783-3

38. Zaydfudim V, Feurer ID, Griffin MR, Phay JE. The impact of lymph node involvement on survival in patients with papillary and follicular thyroid carcinoma. Surgery (2008) 144:1070-7; discussion:7-8. doi: 10.1016/j.surg.2008.08.034

39. Pereira JA, Jimeno J, Miquel J, Iglesias M, Munne A, Sancho JJ, et al. Nodal yield, morbidity, and recurrence after central neck dissection for papillary thyroid carcinoma. Surgery (2005) 138:1095-100; discussion:100-1. doi: 10.1016/j.surg.2005.09.013

40. Sancho JJ, Lennard TW, Paunovic I, Triponez F, Sitges-Serra A. Prophylactic central neck disection in papillary thyroid cancer: a consensus report of the
European Society of Endocrine Surgeons (ESES). Langenbecks Arch Surg. (2014) 399:155-63. doi: 10.1007/s00423-013-1152-8

41. Jeong HS, Baek CH, Son YI, Choi JY, Kim HJ, Ko YH, et al. Integrated 18F-FDG PET/CT for the initial evaluation of cervical node level of patients with papillary thyroid carcinoma: comparison with ultrasound and contrast-enhanced CT. Clin Endocrinol. (2006) 65:402-7. doi: 10.1111/j.1365-2265.2006.02612.x

42. Ahn JE, Lee JH, Yi JS, Shong YK, Hong SJ, Lee DH, et al. Diagnostic accuracy of CT and ultrasonography for evaluating metastatic cervical lymph nodes in patients with thyroid cancer. World J Surg. (2008) 32:1552-8. doi: 10.1007/s00268-008-9588-7

43. Kim E, Park JS, Son K-R, Kim JH, Jeon SJ. Preoperative diagnosis of cervical metastatic lymph nodes in papillary thyroid carcinoma: comparison of ultrasound, computed tomography, and combined ultrasound with computed tomography. Thyroid (2008) 18:411-8. doi: 10.1089/thy.2007.0269

44. Sugitani I, Fujimoto Y, Yamada K, Yamamoto N. Prospective outcomes of selective lymph node dissection for papillary thyroid carcinoma based on preoperative ultrasonography. World J Surg. (2008) 32:2494-502. doi: 10.1007/s00268-008-9711-9

45. Choi YJ, Yun JS, Kook SH, Jung EC, Park YL. Clinical and imaging assessment of cervical lymph node metastasis in papillary thyroid carcinomas. World J Surg. (2010) 34:1494-9. doi: 10.1007/s00268-010-0541-1

46. Lee K, Kawata R, Nishikawa S, Yoshimura K, Takenaka H. Diagnostic criteria of ultrasonographic examination for lateral node metastasis of papillary thyroid carcinoma. Acta Otolaryngol. (2010) 130:161-6. doi: 10.3109/00016480903015143

47. Hwang HS, Orloff LA. Efficacy of preoperative neck ultrasound in the detection of cervical lymph node metastasis from thyroid cancer. Laryngoscope (2011) 121:487-91. doi: 10.1002/lary.21227

48. Lee DW, Ji YB, Sung ES, Park JS, Lee YJ, Park DW, et al. Roles of ultrasonography and computed tomography in the surgical management of cervical lymph node metastases in papillary thyroid carcinoma. Eur J Surg Oncol. (2013) 39:191-6. doi: 10.1016/j.ejso.2012.07.119

49. Yoo YH, Kim JA, Son EJ, Youk JH, Kwak JY, Kim EK, et al. Sonographic findings predictive of central lymph node metastasis in patients with papillary thyroid carcinoma: influence of associated chronic lymphocytic thyroiditis on the diagnostic performance of sonography. J Ultrasound Med. (2013) 32:2145-51. doi: 10.7863/ultra.32.12.2145

50. Lesnik D, Cunnane ME, Zurakowski D, Acar GO, Ecevit C, Mace A, et al. Papillary thyroid carcinoma nodal surgery directed by a preoperative radiographic map utilizing CT scan and ultrasound in all primary and reoperative patients. Head Neck (2014) 36:191-202. doi: 10.1002/hed. 23277

51. Lee YJ, Kim DW, Park HK, Kim DH, Jung SJ, Oh M, et al. Pre-operative ultrasound diagnosis of nodal metastasis in papillary thyroid carcinoma patients according to nodal compartment. Ultrasound Med Biol. (2015) 41:1294-300. doi: 10.1016/j.ultrasmedbio.2015.01.003

52. Khokhar MT, Day KM, Sangal RB, Ahmedli NN, Pisharodi LR, Beland $\mathrm{MD}$, et al. Preoperative high-resolution ultrasound for the assessment of malignant central compartment lymph nodes in papillary thyroid cancer. Thyroid (2015) 25:1351-4. doi: 10.1089/thy.2015.0176

53. Wada N, Duh QY, Sugino K, Iwasaki H, Kameyama K. Lymph node metastasis from 259 papillary thyroid microcarcinomas: frequency, pattern of occurrence and recurrence, and optimal strategy for neck dissection. Ann Surg. (2003) 237:399-407. doi: 10.1097/01.SLA.0000055273.58908.19

54. Pelizzo MR, Boschin IM, Toniato A, Piotto A, Bernante P, Pagetta C, et al. Papillary thyroid microcarcinoma (PTMC): prognostic factors, management and outcome in 403 patients. Eur J Surg Oncol. (2006) 32:11448. doi: 10.1016/j.ejso.2006.07.001

55. Hay ID, Hutchinson ME, Gonzalez-Losada T, McIver B, Reinalda ME, Grant CS, et al. Papillary thyroid microcarcinoma: a study of 900 cases observed in a 60-year period. Surgery (2008) 144:980-7; discussion:7-8. doi: 10.1016/j.surg.2008.08.035

56. Besic N, Zgajnar J, Hocevar M, Petric R. Extent of thyroidectomy and lymphadenectomy in 254 patients with papillary thyroid microcarcinoma: a single-institution experience. Ann Surg Oncol. (2009) 16:920-8. doi: 10.1245/s10434-009-0332-9 
57. Mercante G, Frasoldati A, Pedroni C, Formisano D, Renna L. Prognostic factors affecting neck lymph node recurrence and distant metastasis in papillary microcarcinoma of the thyroid: results of a study in 445 patients. Thyroid (2009) 19:707-16. doi: 10.1089/thy.2008.0270

58. So YK, Son YI, Hong SD, Seo MY, Baek CH, Jeong HS, et al. Subclinical lymph node metastasis in papillary thyroid microcarcinoma: a study of 551 resections. Surgery (2010) 148:526-31. doi: 10.1016/j.surg.2010.01.003

59. Moon HJ, Kim EK, Chung WY, Yoon JH, Kwak JY. Minimal extrathyroidal extension in patients with papillary thyroid microcarcinoma: is it a real prognostic factor? Ann Surg Oncol. (2011) 18:1916-23. doi: 10.1245/s10434-011-1556-Z

60. Londero SC, Krogdahl A, Bastholt L, Overgaard J, Trolle W, Pedersen HB, et al. Papillary thyroid microcarcinoma in Denmark 1996-2008: a national study of epidemiology and clinical significance. Thyroid (2013) 23:1159-64. doi: 10.1089/thy.2012.0595

61. Lee J, Park JH, Lee CR, Chung WY, Park CS. Long-term outcomes of total thyroidectomy versus thyroid lobectomy for papillary thyroid microcarcinoma: comparative analysis after propensity score matching. Thyroid (2013) 23:1408-15. doi: 10.1089/thy.2012.0463

62. Gschwandtner E, Klatte T, Swietek N, Bures C, Kober F, Ott J, et al. Increase of papillary thyroid microcarcinoma and a plea for restrictive treatment: a retrospective study of 1,391 prospective documented patients. Surgery (2016) 159:503-11. doi: 10.1016/j.surg.2015.06.015

63. Kim SK, Park I, Woo JW, Lee JH, Choe JH, Kim JH, et al. Predictive Factors for Lymph Node Metastasis in Papillary Thyroid Microcarcinoma. Ann Surg Oncol. (2016) 23:2866-73. doi: 10.1245/s10434-016-5225-0

64. Cecoli F, Ceresola EM, Altrinetti V, Cabria M, Cappagli M, Montepagani A, et al. Therapeutic strategies and clinical outcome in papillary thyroid microcarcinoma: a multicenter observational study. Eur Thyroid J. (2016) 5:180-6. doi: 10.1159/000446746

65. Kim SK, Park I, Woo JW, Lee JH, Choe JH, Kim JH, et al. Total thyroidectomy versus lobectomy in conventional papillary thyroid microcarcinoma: analysis of 8,676 patients at a single institution. Surgery (2017) 161:485-92. doi: 10.1016/j.surg.2016.07.037

66. Yeh MW, Bauer AJ, Bernet VA, Ferris RL, Loevner LA, Mandel SJ, et al. American Thyroid Association statement on preoperative imaging for thyroid cancer surgery. Thyroid (2015) 25:3-14. doi: 10.1089/thy.2014.0096

67. Monteiro R, Han A, Etiwy M, Swearingen A, Krishnamurthy V, Jin J, et al. Importance of surgeon-performed ultrasound in the preoperative nodal assessment of patients with potential thyroid malignancy. Surgery (2018) 163:112-7. doi: 10.1016/j.surg.2017.10.005

68. Kumbhar SS, O’Malley RB, Robinson TJ, Maximin S, Lalwani N. Why thyroid surgeons are frustrated with radiologists: lessons learned from pre- and postoperative US. Radiographics (2016) 36:2141-53. doi: 10.1148/rg.2016150250

69. Carneiro-Pla D, Amin S. Comparison between preconsultation ultrasonography and office surgeon-performed ultrasound in patients with thyroid cancer. World J Surg. (2014) 38:622-7. doi: 10.1007/s00268-013-2251-y

70. Oltmann SC, Schneider DF, Chen H, Sippel RS. All thyroid ultrasound evaluations are not equal: sonographers specialized in thyroid cancer correctly label clinical N0 disease in well differentiated thyroid cancer. Ann Surg Oncol. (2015) 22:422-8. doi: 10.1245/s10434-014-4089-4

71. Sugitani I, Toda K, Yamada K, Yamamoto N, Ikenaga M, Fujimoto Y. Three distinctly different kinds of papillary thyroid microcarcinoma should be recognized: our treatment strategies and outcomes. World J Surg. (2010) 34:1222-31. doi: 10.1007/s00268-009-0359-x

72. Ito Y, Miyauchi A, Kihara M, Higashiyama T, Kobayashi K, Miya A. Patient age is significantly related to the progression of papillary microcarcinoma of the thyroid under observation. Thyroid (2014) 24:27-34. doi: 10.1089/thy.2013.0367

73. Jeon MJ, Kim WG, Choi YM, Kwon H, Lee YM, Sung TY, et al. Features Predictive of Distant Metastasis in Papillary Thyroid Microcarcinomas. Thyroid (2016) 26:161-8. doi: 10.1089/thy.2015.0375

74. Xu B, Ibrahimpasic T, Wang L, Sabra MM, Migliacci JC, Tuttle RM, et al. Clinicopathologic features of fatal non-anaplastic follicular cellderived thyroid carcinomas. Thyroid (2016) 26:1588-97. doi: 10.1089/thy. 2016.0247
75. Ito Y, Uruno T, Nakano K, Takamura Y, Miya A. An observation trial without surgical treatment in patients with papillary microcarcinoma of the thyroid. Thyroid (2003) 13:381-7. doi: 10.1089/105072503321669875

76. Ito Y, Miyauchi A, Inoue H, Fukushima M, Kihara M, Higashiyama T, et al. An observational trial for papillary thyroid microcarcinoma in Japanese patients. World J Surg. (2010) 34:28-35. doi: 10.1007/s00268-009-0303-0

77. Ghajar CM, Bissell MJ. Pathways of parallel progression Metastasis. Nature (2016) 540:528-9. doi: 10.1038/nature21104

78. Kim H, Kim TH, Choe JH, Kim JH, Kim JS, Oh YL, et al. Patterns of initial recurrence in completely resected papillary thyroid carcinoma. Thyroid (2017) 27:908-14. doi: 10.1089/thy.2016.0648

79. Mehanna H, Al-Maqbili T, Carter B, Martin E, Campain N, Watkinson J, et al. Differences in the recurrence and mortality outcomes rates of incidental and nonincidental papillary thyroid microcarcinoma: a systematic review and meta-analysis of 21329 person-years of follow-up. J Clin Endocrinol Metab. (2014) 99:2834-43. doi: 10.1210/jc.2013-2118

80. Sun W, Lan X, Zhang H, Dong W, Wang Z, He L, et al. Risk factors for central lymph node metastasis in CN0 papillary thyroid carcinoma: a systematic review and meta-analysis. PLoS ONE (2015) 10:e0139021. doi: 10.1371/journal.pone.0139021

81. McAllister SS, Weinberg RA. The tumour-induced systemic environment as a critical regulator of cancer progression and metastasis. Nat Cell Biol. (2014) 16:717-27. doi: 10.1038/ncb3015

82. Bissell MJ, Hines WC. Why don't we get more cancer? A proposed role of the microenvironment in restraining cancer progression. Nat Med. (2011) 17:320-9. doi: 10.1038/nm.2328

83. Valastyan S, Weinberg RA. Tumor metastasis: molecular insights and evolving paradigms. Cell (2011) 147:275-92. doi: 10.1016/j.cell.2011.09.024

84. Wirtz D, Konstantopoulos K, Searson PC. The physics of cancer: the role of physical interactions and mechanical forces in metastasis. Nat Rev Cancer (2011) 11:512-22. doi: 10.1038/nrc3080

85. Oda H, Miyauchi A, Ito Y, Yoshioka K, Nakayama A, Sasai H, et al. Incidences of unfavorable events in the management of low-risk papillary microcarcinoma of the thyroid by active surveillance versus immediate surgery. Thyroid (2016) 26:150-5. doi: 10.1089/thy.2015.0313

86. Durante C, Attard M, Torlontano M, Ronga G, Monzani F, Costante G, et al. Identification and optimal postsurgical follow-up of patients with very low-risk papillary thyroid microcarcinomas. J Clin Endocrinol Metab. (2010) 95:4882-8. doi: 10.1210/jc.2010-0762

87. Miyauchi A, Kudo T, Ito Y, Oda H, Sasai H, Higashiyama $\mathrm{T}$, et al. Estimation of the lifetime probability of disease progression of papillary microcarcinoma of the thyroid during active surveillance. Surgery (2018) 163:48-52. doi: 10.1016/j.surg.2017.03.028

88. Siddiqui S, White MG, Antic T, Grogan RH, Angelos P, Kaplan EL, et al. Clinical and pathologic predictors of lymph node metastasis and recurrence in papillary thyroid microcarcinoma. Thyroid (2016) 26:807-15. doi: 10.1089/thy.2015.0429

89. Tomoda C, Sugino K, Matsuzu K, Uruno T, Ohkuwa K, Kitagawa W, et al. Cervical lymph node metastases after thyroidectomy for papillary thyroid carcinoma usually remain stable for years. Thyroid (2016) 26:1706-11. doi: 10.1089/thy.2016.0225

90. Emanuel EJ, Wendler D, Grady C. What makes clinical research ethical? JAMA (2000) 283:2701-11. doi: 10.1001/jama.283.20.2701

91. Stack BC Jr, Angelos P. The ethics of disclosure and counseling of patients with thyroid cancer. JAMA Otolaryngol Head Neck Surg (2015) 141:957-8. doi: 10.1001/jamaoto.2015.2419

92. Morris LG, Wong RJ, Tuttle RM. Ethical considerations when counseling patients with thyroid cancer about surgery vs observation. JAMA Otolaryngol Head Neck Surg. (2016) 142:406-7. doi: 10.1001/jamaoto.2016.0038

93. Leboulleux S, Tuttle RM, Pacini F, Schlumberger M. Papillary thyroid microcarcinoma and active surveillance - Authors' reply. Lancet Diabetes Endocrinol. (2016) 4:976-7. doi: 10.1016/s2213-8587(16)30326-6

94. Kim SC, Kim JH, Choi SH, Yun TJ, Wi JY, Kim SA, et al. Off-site evaluation of three-dimensional ultrasound for the diagnosis of thyroid nodules: comparison with two-dimensional ultrasound. Eur Radiol. (2016) 26:3353-60. doi: 10.1007/s00330-015-4193-2

95. Yi YS, Kim SS, Kim WJ, Bae MJ, Kang JH, Choi BG, et al. Comparison of twoand three-dimensional sonography for the prediction of the extrathyroidal 
extension of papillary thyroid carcinomas. Korean J Intern Med. (2016) 31:313-22. doi: 10.3904/kjim.2014.363

96. Slapa RZ, Jakubowski WS, Slowinska-Srzednicka J, Szopinski KT. Advantages and disadvantages of 3D ultrasound of thyroid nodules including thin slice volume rendering. Thyroid Res. (2011) 4:1. doi: 10.1186/1756-6614-4-1

97. Park YJ, Kim JA, Son EJ, Youk JH, Park CS. Quantitative shear wave elastography as a prognostic implication of papillary thyroid carcinoma (PTC): elasticity index can predict extrathyroidal extension (ETE). Ann Surg Oncol. (2013) 20:2765-71. doi: 10.1245/s10434-013-2927-4

98. Jung WS, Kim JA, Son EJ, Youk JH, Park CS. Shear wave elastography in evaluation of cervical lymph node metastasis of papillary thyroid carcinoma: elasticity index as a prognostic implication. Ann Surg Oncol. (2015) 22:111-6. doi: 10.1245/s10434-014-3627-4

99. Azizi G, Keller JM, Mayo ML, Piper K, Puett D, Earp KM, et al. Shear wave elastography and cervical lymph nodes: predicting malignancy. Ultrasound Med Biol. (2016) 42:1273-81. doi: 10.1016/j.ultrasmedbio.2016.01.012

100. Xu JM, Xu XH, Xu HX, Zhang YF, Guo LH, Liu LN, et al. Prediction of cervical lymph node metastasis in patients with papillary thyroid cancer using combined conventional ultrasound, strain elastography, and acoustic radiation force impulse (ARFI) elastography. Eur Radiol. (2016) 26:2611-22. doi: 10.1007/s00330-015-4088-2

101. Liu X, Ouyang D, Li H, Zhang R, Lv Y. Papillary thyroid cancer: dualenergy spectral CT quantitative parameters for preoperative diagnosis of metastasis to the cervical lymph nodes. Radiology (2015) 275:167-76. doi: 10.1148/radiol.14140481

102. Hao Y, Pan C, Chen W, Li T, Zhu W, Qi J. Differentiation between malignant and benign thyroid nodules and stratification of papillary thyroid cancer with aggressive histological features: Whole-lesion diffusionweighted imaging histogram analysis. J Magn Reson Imaging (2016) 44:154655. doi: $10.1002 /$ jmri.25290

103. Meyer HJ, Schob S, Hohn AK, Surov A. MRI texture analysis reflects histopathology parameters in thyroid cancer - a first preliminary study. Transl Oncol. (2017) 10:911-6. doi: 10.1016/j.tranon.2017.09.003

104. Schob S, Meyer HJ, Dieckow J, Pervinder B, Pazaitis N, Hohn AK, et al. Histogram analysis of diffusion weighted imaging at $3 \mathrm{~T}$ is useful for prediction of lymphatic metastatic spread, proliferative activity, and cellularity in thyroid cancer. Int J Mol Sci. (2017) 18:E821. doi: 10.3390/ijms18040821

105. Hirokawa M, Kudo T, Ota H, Suzuki A, Miyauchi A. Pathological characteristics of low-risk papillary thyroid microcarcinoma with progression during active surveillance. Endocr J. (2016) 63:805-10. doi: 10.1507/endocr..EJ16-0097

106. Xing M. BRAF mutation in thyroid cancer. Endocr Relat Cancer (2005) 12:245-62. doi: $10.1677 /$ erc. 1.0978

107. Xing M. BRAF mutation in papillary thyroid cancer: pathogenic role, molecular bases, and clinical implications. Endocr Rev. (2007) 28:742-62. doi: 10.1210/er.2007-0007

108. Hou P, Liu D, Xing M. Genome-wide alterations in gene methylation by the BRAF V600E mutation in papillary thyroid cancer cells. Endocr Relat Cancer (2011) 18:687-97. doi: 10.1530/ERC-11-0212

109. Hu S, Liu D, Tufano RP, Carson KA, Rosenbaum E, Cohen Y, et al. Association of aberrant methylation of tumor suppressor genes with tumor aggressiveness and BRAF mutation in papillary thyroid cancer. Int $J$ Cancer (2006) 119:2322-9. doi: 10.1002/ijc.22110

110. Li F, Chen G, Sheng C, Gusdon AM, Huang Y, Lv Z, et al. BRAFV600E mutation in papillary thyroid microcarcinoma: a meta-analysis. Endocr Relat Cancer (2015) 22:159-68. doi: 10.1530/ERC-14-0531

111. Lee DY, Hwang SM, An JH, Son KR, Baek SK, Kim SG, et al. Predicting Extrathyroidal Extension in Patients With Papillary Thyroid Microcarcinoma According to a BRAF Mutation. Clin Exp Otorhinolaryngol. (2017) 10:174-80. doi: 10.21053/ceo.2015.01655

112. Chen Y, Sadow PM, Suh H, Lee KE, Choi JY, Suh YJ, et al. BRAF(V600E) Is correlated with recurrence of papillary thyroid microcarcinoma: a systematic review, multi-institutional primary data analysis, and meta-analysis. Thyroid (2016) 26:248-55. doi: 10.1089/thy.2015.0391

113. Niemeier LA, Kuffner Akatsu H, Song C, Carty SE, Hodak SP, Yip L, et al. A combined molecular-pathologic score improves risk stratification of thyroid papillary microcarcinoma. Cancer (2012) 118:206977. doi: $10.1002 /$ cncr. 26425

114. Yabuta T, Matsuse M, Hirokawa M, Yamashita S, Mitsutake N, Miyauchi A. TERT promoter mutations were not found in papillary thyroid microcarcinomas that showed disease progression on active surveillance. Thyroid (2017) 27:1206-7. doi: 10.1089/thy.2016.0645

115. Li D, Gao M, Li X, Xing M. Molecular aberrance in papillary thyroid microcarcinoma bearing high aggressiveness: identifying a "Tibetan Mastiff Dog" from puppies. J Cell Biochem. (2016) 117:1491-6. doi: $10.1002 /$ jcb. 25506

116. Heidenreich B, Kumar R. TERT promoter mutations in telomere biology. Mutat Res. (2017) 771:15-31. doi: 10.1016/j.mrrev.2016.11.002

117. Pestana A, Vinagre J, Sobrinho-Simoes M, Soares P. TERT biology and function in cancer: beyond immortalisation. J Mol Endocrinol. (2017) 58:R129-46. doi: 10.1530/JME-16-0195

118. Liu X, Bishop J, Shan Y, Pai S, Liu D, Murugan AK, et al. Highly prevalent TERT promoter mutations in aggressive thyroid cancers. Endocr Relat Cancer (2013) 20:603-10. doi: 10.1530/ERC-13-0210

119. Kim TH, Kim YE, Ahn S, Kim JY, Ki CS, Oh YL, et al. TERT promoter mutations and long-term survival in patients with thyroid cancer. Endocr Relat Cancer (2016) 23:813-23. doi: 10.1530/ERC-16-0219

120. Kim TH, Ki CS, Kim HS, Kim K, Choe JH, Kim JH, et al. refining dynamic risk stratification and prognostic groups for differentiated thyroid cancer with TERT promoter mutations. J Clin Endocrinol Metab. (2017) 102:175764. doi: $10.1210 /$ jc.2016-3434

121. Liu C, Liu Z, Chen T, Zeng W, Guo Y, Huang T. TERT promoter mutation and its association with clinicopathological features and prognosis of papillary thyroid cancer: a meta-analysis. Sci Rep. (2016) 6:36990. doi: $10.1038 /$ srep36990

122. Yin DT, Yu K, Lu RQ, Li X, Xu J, Lei M, et al. Clinicopathological significance of TERT promoter mutation in papillary thyroid carcinomas: a systematic review and meta-analysis. Clin Endocrinol. (2016) 85:299-305. doi: $10.1111 /$ cen. 13017

123. Moon S, Song YS, Kim YA, Lim JA, Cho SW, Moon JH, et al. Effects of Coexistent BRAF(V600E) and TERT promoter mutations on poor clinical outcomes in papillary thyroid cancer: a meta-analysis. Thyroid (2017) 27:651-60. doi: 10.1089/thy.2016.0350

124. Liu R, Bishop J, Zhu G, Zhang T, Ladenson PW, Xing M. Mortality risk stratification by combining BRAF V600E and TERT promoter mutations in papillary thyroid cancer: genetic duet of BRAF and TERT promoter mutations in thyroid cancer mortality. JAMA Oncol. (2017) 3:202-208. doi: 10.1001/jamaoncol.2016.3288

125. Liu R, Zhang T, Zhu G, Xing M. Regulation of mutant TERT by BRAF V600E/MAP kinase pathway through FOS/GABP in human cancer. Nat Commun. (2018) 9:579. doi: 10.1038/s41467-018-03033-1

126. de Biase D, Gandolfi G, Ragazzi M, Eszlinger M, Sancisi V, Gugnoni M, et al. TERT promoter mutations in papillary thyroid microcarcinomas. Thyroid (2015) 25:1013-9. doi: 10.1089/thy.2015.0101

127. Boufraqech M, Klubo-Gwiezdzinska J, Kebebew E. MicroRNAs in the thyroid. Best Pract Res Clin Endocrinol Metab. (2016) 30:603-19. doi: 10.1016/j.beem.2016.10.001

128. Zhang R, Hardin H, Chen J, Guo Z, Lloyd RV. Non-coding RNAs in thyroid cancer. Endocr Pathol. (2016) 27:12-20. doi: 10.1007/s12022-016-9417-8

129. Visone R, Russo L, Pallante P, De Martino I, Ferraro A, Leone V, et al. MicroRNAs (miR)-221 and miR-222, both overexpressed in human thyroid papillary carcinomas, regulate p27Kip1 protein levels and cell cycle. Endocr Relat Cancer (2007) 14:791-8. doi: 10.1677/ERC-07-0129

130. Fuziwara CS, Kimura ET. MicroRNA deregulation in anaplastic thyroid cancer biology. Int J Endocrinol. (2014) 2014:743450. doi: $10.1155 / 2014 / 743450$

131. Chruscik A, Lam AK. Clinical pathological impacts of microRNAs in papillary thyroid carcinoma: a crucial review. Exp Mol Pathol. (2015) 99:3938. doi: 10.1016/j.yexmp.2015.08.013

132. Liang L, Zheng X, Hu M, Cui Y, Zhong Q, Wang S, et al. MiRNA-221/222 in thyroid cancer: a meta-analysis. Clin Chim Acta (2018) 484:284-92. doi: 10.1016/j.cca.2018.06.012

133. Lee JC, Zhao JT, Clifton-Bligh RJ, Gill A, Gundara JS, Ip JC, et al. MicroRNA-222 and microRNA-146b are tissue and circulating biomarkers 
of recurrent papillary thyroid cancer. Cancer (2013) 119:4358-65. doi: $10.1002 /$ cncr. 28254

134. Oridate N, Lotan D, Xu XC, Hong WK, Lotan R. Differential induction of apoptosis by all-trans-retinoic acid and $\mathrm{N}$-(4-hydroxyphenyl)retinamide in human head and neck squamous cell carcinoma cell lines. Clin Cancer Res. (1996) 2:855-63.

135. Simon D, Korber C, Krausch M, Segering J, Groth P, Gorges R, et al. Clinical impact of retinoids in redifferentiation therapy of advanced thyroid cancer: final results of a pilot study. Eur J Nucl Med Mol Imaging (2002) 29:775-82. doi: 10.1007/s00259-001-0737-6

136. Xiong Y, Kotian S, Zeiger MA, Zhang L, Kebebew E. miR-126-3p inhibits thyroid cancer cell growth and metastasis, and is associated with aggressive thyroid cancer. PLoS One (2015) 10:e0130496. doi: 10.1371/journal.pone.0130496

137. Yip L, Kelly L, Shuai Y, Armstrong MJ, Nikiforov YE, Carty SE, et al. MicroRNA signature distinguishes the degree of aggressiveness of papillary thyroid carcinoma. Ann Surg Oncol. (2011) 18:2035-41. doi: 10.1245/s10434-011-1733-0

138. Wang Z, Zhang H, He L, Dong W, Li J, Shan Z, et al. Association between the expression of four upregulated miRNAs and extrathyroidal invasion in papillary thyroid carcinoma. Onco Targets Ther. (2013) 6:281-7. doi: 10.2147/OTT.S43014

139. Sun M, Fang S, Li W, Li C, Wang L. Associations of miR-146a and miR-146b expression and clinical characteristics in papillary thyroid carcinoma. Cancer Biomark. (2015) 15:33-40. doi: 10.3233/CBM-140431

140. Qiu Z, Li H, Wang J, Sun C. miR-146a and miR-146b in the diagnosis and prognosis of papillary thyroid carcinoma. Oncol Rep. (2017) 38:2735-40. doi: 10.3892/or.2017.5994

141. Zhang X, Li D, Li M, Ye M, Ding L, Cai H, et al. MicroRNA-146a targets PRKCE to modulate papillary thyroid tumor development. Int $J$ Cancer (2014) 134:257-67. doi: 10.1002/ijc.28141

142. Czajka AA, Wojcicka A, Kubiak A, Kotlarek M, Bakula-Zalewska E, Koperski L, et al. Family of microRNA-146 regulates RARbeta in papillary thyroid carcinoma. PLoS ONE (2016) 11:e0151968. doi: 10.1371 /journal.pone. 0151968

143. He H, Jazdzewski K, Li W, Liyanarachchi S, Nagy R, Volinia S, et al. The role of microRNA genes in papillary thyroid carcinoma. Proc Natl Acad Sci USA. (2005) 102:19075-80. doi: 10.1073/pnas.0509603102

144. Chou CK, Chen RF, Chou FF, Chang HW, Chen YJ. miR-146b is highly expressed in adult papillary thyroid carcinomas with high risk features including extrathyroidal invasion and the BRAF(V600E) mutation. Thyroid (2010) 20:489-94. doi: 10.1089/thy.2009.0027

145. Yang Z, Yuan Z, Fan Y, Deng X, Zheng Q. Integrated analyses of microRNA and mRNA expression profiles in aggressive papillary thyroid carcinoma. Mol Med Rep. (2013) 8:1353-8. doi: 10.3892/mmr. 2013.1699

146. Geraldo MV, Yamashita AS, Kimura ET. MicroRNA miR-146b-5p regulates signal transduction of TGF-beta by repressing SMAD4 in thyroid cancer. Oncogene (2012) 31:1910-22. doi: 10.1038/onc. 2011.381

147. Deng X, Wu B, Xiao K, Kang J, Xie J, Zhang X, et al. MiR-146b$5 p$ promotes metastasis and induces epithelial-mesenchymal transition in thyroid cancer by targeting ZNRF3. Cell Physiol Biochem. (2015) 35:71-82. doi: $10.1159 / 000369676$

148. Chou CK, Chi SY, Huang CH, Chou FF, Huang CC, Liu RT, et al. IRAK1, a target of miR-146b, reduces cell aggressiveness of human papillary thyroid carcinoma. J Clin Endocrinol Metab. (2016) 101:4357-66. doi: 10.1210/jc.2016-2276

149. Peng Y, Li C, Luo DC, Ding JW, Zhang W, Pan G. Expression profile and clinical significance of microRNAs in papillary thyroid carcinoma. Molecules (2014) 19:11586-99. doi: 10.3390/molecules 190811586

150. Diao Y, Fu H, Wang Q. MiR-221 Exacerbate cell proliferation and invasion by targeting TIMP3 in papillary thyroid carcinoma. Am J Ther. (2017) 24:e317-e28. doi: 10.1097/MJT.0000000000000420

151. Huang Y, Yu S, Cao S, Yin Y, Hong S, Guan H, et al. MicroRNA-222 promotes invasion and metastasis of papillary thyroid cancer through targeting protein phosphatase 2 regulatory subunit B alpha expression. Thyroid (2018) 28:1162-73. doi: 10.1089/thy.2017.0665
152. Wang Z, Zhang H, Zhang P, Li J, Shan Z, Teng W. Upregulation of miR-2861 and miR-451 expression in papillary thyroid carcinoma with lymph node metastasis. Med Oncol. (2013) 30:577. doi: 10.1007/s12032-013-0577-9

153. Liu J, Li Q, Li R, Ren P, Dong S. MicroRNA-363-3p inhibits papillary thyroid carcinoma progression by targeting PIK3CA. Am J Cancer Res. (2017) 7:148-58

154. Wang R, Ma Q, Ji L, Yao Y, Ma M, Wen Q. miR-622 suppresses tumor formation by directly targeting VEGFA in papillary thyroid carcinoma. Onco Targets Ther. (2018) 11:1501-9. doi: 10.2147/OTT.S156810

155. Rosignolo F, Memeo L, Monzani F, Colarossi C, Pecce V, Verrienti A, et al. MicroRNA-based molecular classification of papillary thyroid carcinoma. Int J Oncol. (2017) 50:1767-77. doi: 10.3892/ijo.2017.3960

156. Pacifico F, Crescenzi E, Mellone S, Iannetti A, Porrino N, Liguoro D, et al. Nuclear factor- $\{$ kappa $\}$ B contributes to anaplastic thyroid carcinomas through up-regulation of miR-146a. J Clin Endocrinol Metab. (2010) 95:1421-30. doi: 10.1210/jc.2009-1128

157. Bommarito A, Richiusa P, Carissimi E, Pizzolanti G, Rodolico V, Zito G, et al. BRAFV600E mutation, TIMP-1 upregulation, and NF-kappaB activation: closing the loop on the papillary thyroid cancer trilogy. Endocr Relat Cancer (2011) 18:669-85. doi: 10.1530/ERC-11-0076

158. Nixon AM, Provatopoulou X, Kalogera E, Zografos GN, Gounaris A. Circulating thyroid cancer biomarkers: Current limitations and future prospects. Clin Endocrinol. (2017) 87:117-26. doi: 10.1111/cen.13369

159. Yu S, Liu Y, Wang J, Guo Z, Zhang Q, Yu F, et al. Circulating microRNA profiles as potential biomarkers for diagnosis of papillary thyroid carcinoma. J Clin Endocrinol Metab. (2012) 97:2084-92. doi: 10.1210/jc.2011-3059

160. Angell TE, Lechner MG, Smith AM, Martin SE, Groshen SG, Maceri DR, et al. Circulating myeloid-derived suppressor cells predict differentiated thyroid cancer diagnosis and extent. Thyroid (2016) 26:381-9. doi: 10.1089/thy.2015.0289

161. Lubitz CC, Parangi S, Holm TM, Bernasconi MJ, Schalck AP, Suh H, et al. Detection of circulating BRAF(V600E) in patients with papillary thyroid carcinoma. J Mol Diagn. (2016) 18:100-8. doi: 10.1016/j.jmoldx.2015.08.003

162. Condello V, Macerola E, Ugolini C, De Napoli L, Romei C, Materazzi G, et al. Analysis of circulating tumor DNA does not improve the clinical management of patients with locally advanced and metastatic papillary thyroid carcinoma. Head Neck (2018). doi: 10.1002/hed.25155

163. Sui F, Ji M, Hou P. Long non-coding RNAs in thyroid cancer: Biological functions and clinical significance. Mol Cell Endocrinol. (2018) 469:11-22. doi: 10.1016/j.mce.2017.07.020

164. Kim D, Lee WK, Jeong S, Seol MY, Kim H, Kim KS, et al. Upregulation of long noncoding RNA LOC100507661 promotes tumor aggressiveness in thyroid cancer. Mol Cell Endocrinol. (2016) 431:36-45. doi: 10.1016/j.mce.2016.05.002

165. Li H-m. Overexpression of LncRNA HOTAIR is associated with poor prognosis in thyroid carcinoma: a study based on TCGA and GEO data. Hormone Metab Res. (2017) 49:388-99. doi: 10.1055/s-0043-103346

166. Li T, Yang XD, Ye CX, Shen ZL, Yang Y, Wang B, et al. Long noncoding RNA HIT000218960 promotes papillary thyroid cancer oncogenesis and tumor progression by upregulating the expression of high mobility group AT-hook 2 (HMGA2) gene. Cell Cycle (2017) 16:224-31. doi: $10.1080 / 15384101.2016 .1261768$

167. Ma B, Liao T, Wen D, Dong C, Zhou L, Yang S, et al. Long intergenic noncoding RNA 271 is predictive of a poorer prognosis of papillary thyroid cancer. Sci Rep. (2016) 6:36973. doi: 10.1038/srep36973

168. Fu XM, Guo W, Li N, Liu HZ, Liu J. The expression and function of long noncoding RNA IncRNA-ATB in papillary thyroid cancer. Eur Rev Med Pharmacol Sci. (2017) 21:3239-46.

169. Zhou T, Zhong M, Zhang S, Wang Z, Xie R, Xiong C, et al. LncRNA CASC2 expression is down- regulated in papillary thyroid cancer and promotes cell invasion by affecting EMT pathway. Cancer Biomark (2018) 23:185-91. doi: $10.3233 / \mathrm{CBM}-181198$

170. Chen C, Zhou L, Wang H, Chen J, Li W, Liu W, et al. Long noncoding RNA CNALPTC1 promotes cell proliferation and migration of papillary thyroid cancer via sponging miR-30 family. Am J Cancer Res. (2018) 8:192-206.

171. Zhang D, Liu X, Wei B, Qiao G, Jiang T, Chen Z. Plasma lncRNA GAS8-AS1 as a potential biomarker of papillary thyroid carcinoma in chinese patients. Int J Endocrinol. (2017) 2017:2645904. doi: 10.1155/2017/2645904 
172. Xu K, Feng Y. HOXD-AS1 is a predictor of clinical progression and functions as an oncogenic lncRNAs in papillary thyroid cancer. J Cell Biochem (2018). doi: 10.1002/jcb.27809. [Epub ahead of print].

173. Wu X, Yan Y, Li H, Ji N, Yu T, Huang Y, et al. DNA copy number gain-mediated IncRNA LINC01061 upregulation predicts poor prognosis and promotes papillary thyroid cancer progression. Biochem Biophys Res Commun. (2018) 503:1247-53. doi: 10.1016/j.bbrc.2018. 07.032

174. Liu J, Dong H, Yang Y, Qian Y, Liu J, Li Z, et al. Upregulation of long noncoding RNA MALAT1 in papillary thyroid cancer and its diagnostic value. Future Oncol. (2018). doi: 10.2217/fon-2018-0416. [Epub ahead of print].

175. Wang C, Yan G, Zhang Y, Jia X, Bu P. Long non-coding RNA MEG3 suppresses migration and invasion of thyroid carcinoma by targeting of Racl. Neoplasma (2015) 62:541-9. doi: 10.4149/neo_2015_065

176. Lan X, Sun W, Zhang P, He L, Dong W, Wang Z, et al. Downregulation of long noncoding RNA NONHSAT037832 in papillary thyroid carcinoma and its clinical significance. Tumour Biol. (2016) 37:6117-23. doi: 10.1007/s13277-015-4461-4

177. Xia S, Wang C, Ni X, Ni Z, Dong Y. NONHSAT076754 aids ultrasonography in predicting lymph node metastasis and promotes migration and invasion of papillary thyroid cancer cells. Oncotarget (2017) 8:2293-306. doi: 10.18632/oncotarget.13725

178. Ding J, Wang F, Xiang T, Qiao M. Expression and function of long noncoding RNA NONHSAT129183 in papillary thyroid cancer. Oncol Res. (2018) 26:1047-53. doi: 10.3727/096504018X15152037713570

179. Wang Q, Yang H, Wu L, Yao J, Meng X, Jiang H, et al. Identification of specific long non-coding RNA expression: profile and analysis of association with clinicopathologic characteristics and BRAF mutation in papillary thyroid cancer. Thyroid (2016) 26:1719-32. doi: 10.1089/thy.2016.0024
180. Sun W, Lan X, Wang Z, Dong W, He L, Zhang T, et al. Overexpression of long non-coding RNA NR_036575.1 contributes to the proliferation and migration of papillary thyroid cancer. Med Oncol. (2016) 33:102. doi: 10.1007/s12032-016-0816-y

181. Feng K, Liu Y, Xu LJ, Zhao LF, Jia CW, Xu MY. Long noncoding RNA PVT1 enhances the viability and invasion of papillary thyroid carcinoma cells by functioning as ceRNA of microRNA-30a through mediating expression of insulin like growth factor 1 receptor. Biomed Pharmacother. (2018) 104:68698. doi: 10.1016/j.biopha.2018.05.078

182. Du Y, Xia W, Zhang J, Wan D, Yang Z, Li X. Comprehensive analysis of long noncoding RNA-mRNA co-expression patterns in thyroid cancer. Mol Biosyst. (2017) 13:2107-15. doi: 10.1039/c7mb00375g

183. Liyanarachchi S, Li W, Yan P, Bundschuh R, Brock P, Senter L, et al. Genome-wide expression screening discloses long noncoding RNAs involved in thyroid carcinogenesis. J Clin Endocrinol Metab. (2016) 101:4005-13. doi: 10.1210/jc.2016-1991

184. Asa SL, Ezzat S. The epigenetic landscape of differentiated thyroid cancer. Mol Cell Endocrinol. (2018) 469:3-10. doi: 10.1016/j.mce.2017.07.012

Conflict of Interest Statement: The authors declare that the research was conducted in the absence of any commercial or financial relationships that could be construed as a potential conflict of interest.

Copyright $\odot 2018$ Xue, Wang, Hurst, Chang and Chen. This is an open-access article distributed under the terms of the Creative Commons Attribution License (CC BY). The use, distribution or reproduction in other forums is permitted, provided the original author(s) and the copyright owner(s) are credited and that the original publication in this journal is cited, in accordance with accepted academic practice. No use, distribution or reproduction is permitted which does not comply with these terms. 